\title{
How active are we? Levels of routine physical activity in children and adults
}

\author{
M. B. E. Livingstone*, P. J. Robson, J. M. W. Wallace and M. C. McKinley \\ Northern Ireland Centre for Diet and Health, University of Ulster, Coleraine, Co. Londonderry BT52 1SA, UK
}

\begin{abstract}
The accurate measurement of physical activity is fraught with problems in adults, but more especially in children because they have more complex and multi-dimensional activity patterns. In addition, the results of different studies are often difficult to interpret and compare, because of the diversity of methodological approaches, differences in data analysis and reporting, and the adoption of varying definitions of what constitutes an appropriate level of activity. Furthermore, inactivity is seldom quantified directly. Although there exists an extensive literature documenting the health benefits of regular physical activity in adults, activity-health relationships in children are not clear-cut. Current recommendations reinforce the concept of health-related activity, accumulating $30 \mathrm{~min}$ moderate-intensity exercise on at least $5 \mathrm{~d} /$ week (adults) and $1 \mathrm{~h}$ moderateintensity exercise/d (children). Evidence suggests a high prevalence of inactivity in adults, but whether or not inactivity is increasing cannot be assessed currently. Similarly, no definite conclusions are justified about either the levels of physical activity of children, or whether these are sufficient to maintain and promote health. Data to support the belief that activity levels in childhood track into adulthood are weak. Inactivity is associated with an increased risk of weight gain and obesity, but causality remains to be established. In children there is strong evidence to demonstrate a dose-response relationship between the prevalence and incidence of obesity and time spent viewing television. Future research should focus on refining methodology for physical activity assessment to make it more sensitive to the different dimensions and contexts of activity in different age-groups.
\end{abstract}

Adults: Children: Physical activity: Exercise: Tracking: Obesity

The benefits of physical activity are now well documented, at least in adults, and exercise is now included in most health promotion recommendations. Accurate assessment of both patterns and trends in physical activity and inactivity is critical, not only for defining the extent to which activity levels are inadequate and/or declining, but also for informing public health policy and evaluating the progress towards meeting health policy objectives. Consequently, the purpose of the present paper is to review the descriptive epidemiology of physical activity behaviour in children and adults, with special reference to the role of physical inactivity in the aetiology of obesity. Existing gaps in knowledge will be highlighted and suggestions made for further research to better characterize the physical activity behaviours of children and adults.

\section{Definitions}

Physical activity is a complex behaviour that has been difficult to define operationally. Thus, while the terms 'physical activity', 'exercise' and 'physical fitness' are distinct concepts, they have often been used interchangeably in physical activity epidemiology. This confusion in terminology has undoubtedly impeded a full understanding of patterns of physical activity and the health consequences associated with activity and inactivity. The terminology has now been clarified and broad consensus reached on how the definitions should be applied (Caspersen et al. 1985, 1998; Caspersen, 1989; Biddle et al. 1998).

Hence, the umbrella term of physical activity describes any bodily movement produced by contraction of skeletal muscle and resulting in energy expenditure, whereas exercise is a sub-category of physical activity that is "planned, structured and repetitive movements done to improve or maintain one or more components of physical fitness' (Caspersen et al. 1985). Sport is another sub-set of physical activity that involves structured competitive situations, although in Europe the term is often used in a wider context to include both exercise and leisure-time activities. Consequently, according to these widely-accepted definitions,

\footnotetext{
Abbreviations: DLW, doubly-labelled water; HR, heart rate; PAL, physical activity level (total energy expenditure:BMR); TEE, total energy expenditure. *Corresponding author: Dr M. B. E. Livingstone, fax +4428 7032 4965, email mbe.livingstone@ulster.ac.uk
} 
physical activity is a very broad construct that includes almost all kinds of movement, but exercise is a much narrower and more purposeful construct.

While physical activity, exercise and sport may be classified as behaviours, physical fitness is classified as an outcome and is related to the ability to achieve certain performance standards or traits (Caspersen et al. 1985, 1998; Caspersen, 1989; Biddle et al. 1998). Some fitness components are related to sports performance while others are considered health-related fitness outcomes. These healthrelated physical fitness components include cardiovascular endurance, muscular endurance or strength, body composition and flexibility, which, to varying extents, reflect genetic inheritance and age, as well as levels of physical activity.

The dose of physical activity or exercise required to effect a particular health benefit response varies along four basic dimensions. Frequency is described as the number of activity sessions per time period (e.g. day or week). Intensity describes the measured or predicted energy cost associated with physical activity and may be described in relative or absolute terms. Duration may refer to a single bout of physical activity or a cumulative time measure, while type of activity is a qualitative descriptor. The product of the frequency, intensity and duration yields the total energy expenditure (TEE) associated with physical activity and is a measure of the volume of exercise performed.

In the present review physical activity refers to all locomotor physical activity, which involves large muscle groups to move the body around and to apply force to objects. For children this physical activity is mainly incurred through non-structured and structured play and/or sport and/or recreation, active transportation and part-time work pursuits. Adult physical activity is mainly achieved through occupational activity, active transportation, care-giving responsibilities and leisure pursuits. Traditionally, physical activity epidemiologists have been primarily concerned with quantifying activity, whereas the quantification of inactivity is often simply inferred from the absence of active pursuits. However, given that the opportunities to be active are fast disappearing, and that inactivity may exert effects on health, which are independent of the effects of activity (Dietz, 1996), efforts to accurately characterize inactivity merit much more attention than hitherto.

\section{Measurement of physical activity}

The accurate measurement of physical activity is fraught with problems in adults (Melanson \& Freedson, 1996), and more especially children because they have more complex and multi-dimensional activity patterns (Saris, 1986; Baranowski \& Simons-Morton, 1991; Welk et al. 2000). The optimum epidemiological tool for assessing energy expenditure and/or physical activity does not exist. Ideally, such a method should be accurate, precise, objective, simple to use, robust, nonreactive, cause minimal intrusion into habitual activity patterns, socially acceptable, time-efficient, allow continuous and detailed recording of usual activity patterns and, finally, it should be applicable to large population groups.

Moreover, it should effectively measure the health-related dimension(s) which is(are) the focus of concern in a particular study. There are at least five dimensions of physical activity that are associated with specific disease conditions and health outcomes: (1) energy expenditure for assessment of energy balance; (2) aerobic intensity for heart health; (3) weightbearing activity for skeletal health; (4) resistance and endurance activity for muscular strength; (5) high-range movement for flexibility (Caspersen et al. 1985; Caspersen, 1989). The dimensions of activity are fundamentally different from each other and thus, by definition, each requires its own assessment technique. It is also clear that not all dimensions of health-related physical activity are given equal emphasis or, indeed, covered completely in the vast majority of studies, particularly in national surveys (Troiano et al. 2001). Rather, most studies have been concerned with assessment of energy expenditure and/or aerobic capacity, while strengthening and flexibility have received much less attention.

The thirty or so different techniques for assessing freeliving physical activity can be grouped into two broad categories: subjective, which include observation and questionnaires (including activity diaries, recall questionnaires, interviews); objective, which include physiological indices such as heart rate (HR), calorimetry, the doubly-labelled water (DLW) method and electronic motion sensors. Each of these methods has its strengths and limitations and can fulfil one, or more, but rarely all the needs for epidemiological studies of physical activity. Not surprisingly, the need for improvements in methodology for assessing physical activity is a recurring theme in the numerous literature reviews of the subject area (Saris, 1985, 1986; Pate, 1993; Livingstone, 1994; Melanson \& Freedson, 1996; Montoye et al. 1996; Armstrong \& Welsman, 1997).

Observational procedures are only suitable for small and medium sized samples when information on the specific types and duration of activity in a variety of physical and social settings is the primary focus of concern. Because they are not biased by recall or self-reporting ability, these procedures are particularly suitable for young children (Bailey et al. 1995). However, the methodology can be time-consuming, labour intensive and interfere with spontaneous activity patterns and to be effective it requires extreme diligence and control of observer reliability.

For reasons of feasibility and cost, the instruments of choice in both small-scale and large-scale studies of habitual physical activity in adolescents (Riddoch et al. 1990; Sallis et al. 1993; Gregory \& Lowe, 2000) and adults (Jacobs et al. 1993; Philippaerts et al. 1999; Livingstone et al. 2001) are standardized questionnaires (interview administered or self-reported) or diaries. However, diaries and recalls rely on memory, are subject to misrepresentation, particularly socially-desirable responding, and are inconsistent in reliability and validity (Westerterp, 1999a). Accuracy in recalling physical activity may also vary by gender and weight status (Sallis et al. 1985). The utility of these instruments is especially problematic in children $<10$ years of age (Pate, 1993; Sallis \& Owen, 1999) because of cognitive limitations (Harter, 1988), and because their activity patterns tend to be sporadic in terms of intensity and duration (Simons-Morton et al. 1987; Armstrong \& Bray, 1991).

Overall, questionnaires are most useful for assessing patterns, frequency, type and the context of physical activity. In particular, they are probably most effective for 
assessing easily-recalled, structured and time-delineated activities such as participation in sport and routine activities such as walking to school. However, as pointed out by Wareham \& Rennie (1998), the undue emphasis in many questionnaires on sport and other recreational activities has been disproportionate to their true importance. On the other hand, activities of light-to-moderate intensity such as playing out of the home, occupational activities and a range of household tasks are no less important, but are difficult to define, and are even more difficult to recall accurately (Sallis et al. 1985; Hopkins et al. 1991; Ainsworth, 2000). In addition, lower-intensity activities may display a great deal of intra-individual variation, and even if they are included in a survey, their usual patterns may not be characterized fully with just a single time-point assessment. The time frame of activity questionnaires can vary enormously, but in general the shorter the time frame the easier it is to recall, particularly for young children. However, this approach may be at the expense of capturing information about habitual activity patterns, particularly if there are marked seasonal differences in activity patterns.

Currently, the most socially acceptable and powerful technique for providing an objective measure of TEE is the DLW method. As the technique is non-intrusive and measurements are performed over longer periods than with other techniques, typically $\geq 1-2$ weeks, it is more likely to provide a representative estimate of TEE (Schoeller \& Racette, 1990; Murgatroyd et al. 1993). When combined with estimates of BMR, the energy cost of physical activity (TEE - BMR) can be calculated. This approach is of particular importance given that the accurate measurement of this component of TEE has traditionally been elusive under free-living conditions (Stager et al. 1995). However, because its application in large-scale studies is constrained by cost and technical complexity, one of its main uses is as a reference standard against which to assess the validity of other measures of physical activity. Furthermore, in epidemiological studies it may not even be the most appropriate method to apply since it provides no assessment of the patterns of physical activity (type, frequency, duration, intensity), which are important functional indicators of health status.

During the last decade the development of new-generation motion sensors and HR monitors have greatly enhanced the ability to objectively characterize the frequency, duration and intensity of physical activity over extended periods of time. Motion sensors include simple pedometers for counting steps and accelerometers, which quantify either vertical movement (uniaxial) or movement in several planes (triaxial). Pedometers, because they are insensitive to nonlocomotor forms of movement, are best reserved for those studies that aim to document relative changes in physical activity or for ranking subjects into activity levels (Trost, 2001).

Although accelerometers offer considerable promise for providing valid assessments of intermittent activity of both low and high intensity (Eston et al. 1998; Welk et al. 1998), they are relatively new and their definitive validity under field conditions remains to be established (Bouten et al. 1996; Westerterp \& Bouten, 1997; Johnson et al. 1998; Ekelund et al. 2001). In particular, their validity for assessment of resistance exercise and cycling is debatable. At present there is an ongoing debate as to whether triaxial accelerometers provide comparable (Janz, 1994; Welk \& Corbin, 1995), or better (Eston et al. 1998; Westerterp, $1999 b$ ) profiles of physical activity than uniaxial accelerometers. Aside from these issues of validity and precision, the relative size of the most popular accelerometers remains an important practical consideration, particularly for smaller children (Westerterp, 1999a). Moreover, the current cost of accelerometers has, to date, limited their application in large epidemiological studies. The enhanced precision afforded by a combination of HR monitoring and accelerometry holds promise for the future (Treuth et al. 1998).

Although HR can only measure response to activity, and not activity per se, it remains the method of choice for objectively assessing patterns of moderate- and vigorous-intensity activity in small-scale studies. However, at low levels of physical activity the interpretation of HR data is confounded by the fact that HR responses reflect not only physical activity but also the site, kind and intensity of muscle activity, posture, prandial status, state of hydration, ambient temperature, humidity and emotional status (Riddoch et al. 1991; Livingstone, 1997). The relationship between HR and physical activity is more secure at moderate-to-high intensity activity and it is possible to quantify TEE from individually derived $\mathrm{HR} v . \mathrm{O}_{2}$ uptake regression equations, (Livingstone et al. 1990, 1992; Lovelady et al. 1993; Racette et al. 1995; Ekelund et al. 2000) and/or bouts of exercise that might be considered to confer a health benefit (Saris, 1986; Riddoch et al. 1991; Armstrong, 1998). The feasibility of HR for assessing both the pattern and total level of energy expenditure in the epidemiological context has been explored and confirmed by Wareham et al. (1997). However, since individual calibration adds another layer of complexity to the method, an alternative strategy is to apply an arbitrary HR threshold, which is believed to approximate the threshold for health-promoting activity. In this context, a cut-off of 140 beats/min is often adopted for children (Armstrong, 1998).

The measurement of such a highly complex and variable behaviour as physical activity is difficult, but feasible. In particular, a major challenge will be to develop an instrument capable of accurately characterizing the unique, sporadic and diverse activities of children. Unfortunately, definitive reliability and validity studies for many of the methods are lacking. Inevitably, the choice of the most appropriate method to use (aside from considerations of precision and validity) will be dictated largely by practical, financial and logistical considerations. Since each of the methods is deficient in at least one respect, a combination of different techniques should be considered within the context of the available resources, the numbers to be surveyed and the focus of concern of the study.

\section{Why be active?}

\section{Adults}

Epidemiological and experimental evidence has now conclusively demonstrated a strong, independent and inverse relationship between physical activity and/or fitness and a range of health outcomes. Physically-inactive adults 
are at increased risk of CHD (Powell et al. 1987; Berlin \& Colditz, 1990), hypertension (Paffenbarger et al. 1983; Arroll \& Beaglehole, 1992), stroke (Wannamethee \& Shaper, 1992), non-insulin-dependent diabetes mellitus (Helmrich et al. 1991), osteoporosis (Cummings et al. 1985; Wickham et al. 1989), site-specific cancers (Albanes et al. 1989; Lee et al. 1991; Martínez et al. 1997), anxiety and depression (Taylor et al. 1985; Stephens, 1988), as well as all-cause mortality (Paffenbarger et al. 1986; Blair et al. 1989). Compared with an active lifestyle, inactivity doubles the risk of developing CHD and confers a level of risk similar to, and independent of, the other main risk factors, hypertension, dyslipidaemia and cigarette smoking (Powell et al. 1987; Berlin \& Colditz, 1990). However, given that the prevalence of inactivity is much higher than that of the other three risk factors, the public health burden it imposes has much greater importance. At the same time, the reversal and prevention of a sedentary lifestyle offers one of the greatest opportunities for public health improvement.

Overall, while there is an inverse and generally linear relationship between levels of physical activity and rates of all-cause mortality, total cardiovascular disease incidence and mortality and the incidence of non-insulin-dependent diabetes mellitus, the evidence for a graded dose-response relationship for other health outcomes is less securely based (Haskell, 1994; Kesaniemi et al. 2001). In many of the studies the most favourable health outcomes are associated with light-to-moderate intensity physical activity, undertaken on a more intermittent, rather than a continuous, basis, and including such activities as walking (Paffenbarger et al. 1986; Leon et al. 1987), stair-climbing (Paffenbarger et al. 1986) and gardening (Leon et al. 1987). The magnitude of the health benefit of physical activity appears to be inversely associated with baseline activity levels, with the greatest health benefits accruing when chronically-inactive individuals become moderately active (Jennings et al. 1986; Nelson et al. 1986; Paffenbarger et al. 1986; Leon et al. 1987; Reaven et al. 1991; Blair et al. 1992; Blair \& Connelly, 1996). Thereafter, with the exception of some clinical and biological indices, the magnitude of the dose response appears to diminish with further increments in the intensity and amount of activity. Consequently, there may exist an optimum level of activity for a given health outcome, beyond which there are few further benefits, although this level has yet to be defined. Similar relationships between physical fitness and health outcome have also been observed (Blair et al. 1989).

In an effort to reconcile the evolving scientific evidence with levels of physical activity that are realistically achievable by the majority of the population, there has been increasing recognition of the need to expand (but not replace) earlier guidelines that only addressed the amount and type of exercise needed to improve physical fitness (American College of Sports Medicine, 1978). Given that such guidelines are incompatible with the lifestyles and motivation of many of the population and, in any case, are not required to improve the majority of dimensions of health (Blair et al. 1992; Blair \& Connelly, 1996), the emphasis has shifted in favour of healthpromoting physical activity (Table 1). Consequently, the key message of recent recommendations is the accumulation of 30 min moderate-intensity activity (equating to brisk walking
Table 1. Recommendations for health-related physical activity in adults (from Department of Health, 1996)

Take 30 min moderate-intensity physical activity on at least $5 \mathrm{~d} /$ week Ideally these 30 min should be one of sustained activity, but shorter bouts of $15 \mathrm{~min}$ are also beneficial

Examples of moderate-intensity physical activities are: brisk walking, climbing stairs, swimming, social dancing, exercises, heavy DIY, heavy gardening and housework

DIY, 'do-it-yourself' task.

for most individuals) on at least $5 \mathrm{~d} /$ week, and preferably every day of the week (American College of Sports Medicine 1990; Pate et al. 1995; Department of Health and Social Services, 1996; US Department of Health and Human Services, 1996; US Department of Agriculture, Agricultural Research Service, Dietary Guidelines Advisory Committee, 2000). Furthermore, because the total accumulated amount of activity is more important than its intensity or duration (Ebisu, 1985; DeBusk et al. 1990; Murphy \& Hardman, 1998), the benefits can be achieved by undertaking intermittent bouts of a variety of structured and unstructured activities. At the same time, it should be noted that the current guidelines, with their emphasis on a generally active lifestyle, are not intended to replace the earlier advice to undertake vigorous activity for $20 \mathrm{~min}$ on at least three occasions per week in order to enhance or maintain aerobic capacity. Moreover, there is currently insufficient knowledge to specify what is an optimal or hazardous level of physical activity.

From a public health point of view, therefore, it makes sense to promote activity that can be readily incorporated into the lifestyle of the least active segment of the population since they are the greatest health risk and have the most to gain. This shift in emphasis has important public health implications since it provides more flexibility in designing and implementing physical activity programmes. However, achieving this shift is not likely to be easy.

\section{Children}

Although there is now an extensive and compelling literature documenting the health benefits of regular physical activity in adults, the relationships between activity and health in children are far from clear-cut, even though conventional wisdom might suggest otherwise (Vaccaro \& Mahon, 1989; Baranowski et al. 1992; Barnard \& Wen, 1994; Bar-Or, 1994; Sallis \& Patrick, 1994; Borer, 1995; Chilibeck et al. 1995; Rowland, 1996). Thus, at present there is no firm scientific underpinning to the recommendations about the amounts and types of physical activity necessary for the promotion and maintenance of health during childhood and adolescence. Rather, because of methodological and conceptual constraints, current guidelines borrow heavily from the evidence gleaned from studies of the health benefits of activity in adults.

Blair et al. (1989) have hypothesized the possible relationships between activity levels, health and stage in the lifespan, leading to three possible benefits during the paediatric years: (1) to enhance physiological and psychological development, which will have immediate and direct 
spin-offs for childhood health status and quality of life; (2) to delay or retard the evolution of health risk factors in order to minimize risks of future degenerative disease in adulthood; (3) to establish and maintain adequate levels of physical activity throughout life.

Unfortunately, the evidence to demonstrate the beneficial health effects of childhood activity, over inactivity, is far from convincing. In fact, this outcome is hardly surprising because disease and mortality resulting from inappropriate activity and/or dietary patterns are rare in children, with the result that it is difficult to demonstrate any deleterious effects from these behaviours (with the exception of obesity). In contrast to adults where disease end points are commonly used to establish activity-health relationships, in children disease risk markers are typically used. Even then, the relationships between inactivity and disease risk end points may be subtle and escape detection, particularly if there has been insufficient time for inactivity to adversely impact on risk indices.

Of all the associations between health outcomes and physical activity, it is reasonable to expect that the physical activity-obesity association would be high. Although some cross-sectional studies have found an inverse relationship between physical activity and BMI or skinfold measurements, others have found no relationship (Bar-Or \& Baranowski, 1994; Riddoch, 1998). In any case, even if an inverse relationship has been established, it is not possible to determine the direction of the association (i.e. is a low level of physical activity a cause or consequence of increased adiposity?). The escalating rates of paediatric obesity (Troiano et al. 1995; Livingstone, 2000; Chinn \& Rona, 2001) are now a major public health concern since childhood obesity tends to track into adulthood (Serdula et al. 1993; Whitaker et al. 1997) and is associated with a range of shortand long-term deleterious physiological and psychological consequences (Schonfeld-Warden \& Warden, 1997; Vanhala et al. 1998; Must \& Strauss, 1999). Irrespective of adult weight status, adults who were obese as children experience increased morbidity and mortality (Must et al. 1992). Thus, while the exact role of a sedentary lifestyle in the aetiology of childhood obesity has not been clarified, there are compelling arguments why a physically-active lifestyle should feature prominently in its treatment and prevention.

Similarly, in relation to the modifiable risk factors for cardiovascular disease, there is no strong empirical evidence to show that physical activity or fitness will result in a more favourable blood lipid profile (Armstrong \& Simons-Morton, 1994; Webber et al. 1996; Boreham et al. 1997). It has also been concluded that in normotensive children exercise training is only weakly related to blood pressure (Alpert \& Wilmore, 1994), although aerobic training has a lowering effect on blood pressure in hypertensive adolescents (Hagberg et al. 1983; Danforth et al. 1990; Hansen et al. 1991).

While physical activity is an essential stimulus for bone structure, knowledge about the long-term effects of childhood physical activity on bone accretion is incomplete. Weight-bearing physical activity is an important predictor of bone mineral density (Bailey \& Martin, 1994; Bailey et al. 1996), although weakly beneficial effects have also been noted for low impact activities. Thus, while activity can enhance a range of variables related to skeletal development in children, the critical period(s) within childhood, as well as the optimal type and volume of activity required to optimize bone accretion, have yet to be defined.

One widely held perception is that active children become active adults, that there is an inoculation that leads individuals to pursue a lifetime of physical activity. This issue is discussed in detail later in the present review (see p. 693) but, in summary, the existing data do not strongly support the contention that adult physical activity patterns are established during childhood (Malina, 1996). In fact, the majority of the tracking data show only weak carry-over effects.

In contrast to the inconclusive and weak evidence that physical activity benefits the physical health of children, the evidence for psychological and social benefits is more securely based and these may far outweigh those of diminishing risk for future disease. Physical activity has been shown to enhance psychological well-being (Steptoe \& Butler, 1996; Gordon \& Grant, 1997), reduce symptoms of depression and anxiety (Calfas \& Taylor, 1994) and offer opportunities for promoting self-esteem, particularly in children who are dis- advantaged and with low initial self-regard (Gruber, 1986). However, undue emphasis on competitive performance could negate some of these potential benefits (Shields \& Bredemeier, 1994).

Given the tenuous nature of the existing evidence in support of the beneficial health effects of activity in childhood and adolescence, it is not surprising that researchers and public health policy makers have struggled to find a compelling rationale on which to base definitive activity recommendations for children. Although this situation is not encouraging, as pointed out by Riddoch (1998), the weaknesses of the existing data can be rationalized from a combination of biological, epidemiological, behavioural and conceptual perspectives. First, the associations that do exist generally advocate in favour of the beneficial role of physical activity. Second, even if no relationship can be demonstrated, this position should not necessarily be interpreted that such a relationship does not exist, or that exercise will not prevent the development of risk factors in due course. Third, direct proof of a cause-effect relationship should not always be deemed a necessary prerequisite for making certain assumptions about health outcomes, or for adopting a laissez-faire attitude. Aside from these issues, intuition and common sense dictate that there are many reasons, beyond those of present and future physical health, for promoting an active lifestyle in children. As Blair et al. (1989) have argued, the primary focus of exercise promotion should be to establish a commitment to an active lifestyle, which will persist across the lifespan. There are few researchers and policy makers who would contest the logic and appeal of this argument and, moreover, it circumvents the need to define and justify recommendations based on insecure associations between activity and health risk indicators.

Consequently, current US (Sallis \& Patrick, 1994; US Department of Health and Human Services, 1996) and UK (Biddle et al. 1998) recommendations for activity by children and adolescents now reinforce the concept of health-related activity, in contrast to earlier criteria that 
Table 2. Recommendations for health-related physical activity in children and adolescents (5-18 years) (from Health Education Authority, 1999)

All children and adolescents should participate in physical activity of at least moderate intensity for $1 \mathrm{~h} / \mathrm{d}$

Children and adolescents who currently do little activity should participate in physical activity of at least moderate intensity for at least $30 \mathrm{~min} / \mathrm{d}$

At least twice per week, some of these activities should help to enhance and maintain muscular strength and flexibility, and bone health

prioritized the development of cardiovascular fitness based on adult fitness training guidelines. It is now recognized that meeting the latter criteria may not be necessary for achieving a direct health benefit and, additionally, they are likely to be incompatible with the exercise motivations and patterns of many children (Cale \& Harris, 1993; Riddoch \& Boreham, 1995). Instead, the need to be physically active on a regular basis is now stressed and the primary recommendation is for children and adolescents to accumulate $1 \mathrm{~h}$ of moderate-intensity activity per $\mathrm{d}$, such activities to include those that promote muscle strength, flexibility and bone health (Table 2). However, given the escalating problem of paediatric obesity, the importance of total activity energy expenditure, (i.e. the totality of physical activity) may need to be given greater priority in future recommendations. The guidelines represent the clearest international consensus on this issue to date and take cognizance of the wide range of forms and settings in which physical activity can be performed.

\section{How active are we?}

\section{Adults}

During the course of the last century, major changes in lifestyle have had a profound impact on patterns of energy expenditure and physical activity in affluent countries. Increased mechanization in the workplace has markedly reduced the need for moderate- and high-intensity activity, to the extent that $>80 \%$ of the men and $>90 \%$ of the women are now engaged in sedentary occupations. In the home the energy cost of housework has also been minimized, while at the same time television viewing and related pursuits now monopolize much of the available leisure time of a substantial proportion of the population. As a result of this modern technology and increased affluence, predominantly sedentary populations can achieve energy equilibrium at a level of energy expenditure below that considered optimal for health.

Population studies: self-report. Population level data on self-reported patterns of physical activity now exist for several countries. However, while physical activity is a complex behaviour that encompasses activity arising from work, household tasks, self-care and care-giving tasks, transportation and discretionary leisure time, it is apparent that not all these aspects of physical activity are given equal emphasis or covered comprehensively in national surveys.
The over-riding focus in many of the studies has been on the assessment of leisure-time activity, often to the exclusion of occupational activity and other activities of daily living. Even when the focus is on leisure-time activity, the data can be highly variable in both detail and completeness. Furthermore, inactivity is often not measured direct, rather sedentariness is simply inferred as the absence of active pursuits.

Thus, while it is possible to generalize about leisure-time practices at national and subgroup level, definitive statements about the prevalence (or lack of) beneficial physical activity are precluded in many studies.

In England the most recent data on both leisure and occupational activity habits have been obtained by merging the baseline data from the Allied Dunbar National Fitness Survey and the Health Education Authority National Survey of Activity and Health (Fentem \& Walker, 1995) to give a database on approximately 6500 adults aged 16-74 years. Activities that were excluded from the analysis included light housework, care-giving tasks and stair climbing. Using a criterion measure for sedentary activity of less than one $30 \mathrm{~min}$ period of moderate-intensity activity per week, the survey revealed the high prevalence of a sedentary lifestyle in men $(29 \%)$ and women $(28 \%)$. A further $36 \%$ of the men and $24 \%$ of the women were regularly active at moderate intensity (active for at least $30 \mathrm{~min}$ per occasion on five or more occasions per week in the previous 4 weeks), while only $16 \%$ of the men and $5 \%$ of the women achieved the activity target for vigorous physical activity.

In the USA physical activity surveillance data and trends are collected as part of three major national surveys on health and health behaviour: the National Health Interview Survey (US Department of Health and Human Services, 1996; Jones et al. 1998); the Behavioral Risk Factor Surveillance System (Remington et al. 1988; Centers for Disease Control, 1995); the National Health and Nutrition Examination Survey (Crespo et al. 1996). Although, until recently, these surveys have been primarily concerned with providing data on leisure-time activity, they show that inactivity is also a major public health problem in the USA. While the prevalence estimates vary between surveys, it appears that $23-40 \%$ of the US adults are sedentary in their leisure time. For example, the most recent national data from the 1998 Behavioral Risk Factor Surveillance System indicated that $30 \%$ of the adults are inactive during leisure time, a further $43 \%$ participate in some activity, but of insufficient intensity to achieve a health benefit, leaving $27 \%$ who are physically active at recommended levels (Macera \& Pratt, 2000). Similar to the data from England, about $13 \%$ of the adults meet the recommended levels of activity for the promotion of cardiovascular fitness $(\geq 20 \mathrm{~min}$ of vigorous intensity activity three or more times per week).

Although cross-country comparisons are necessarily tenuous because of methodological differences between studies, broadly similar patterns of activity to England and the USA have been observed in Australia and Canada (Stephens \& Caspersen, 1994). However, data from Finland suggest that $50 \%$ of the adult population are at least moderately active, while $15 \%$ are classified as highly active (Stephens \& Caspersen, 1994). 
Unfortunately, there are no good longitudinal trend data on physical activity. Examination of national trends in leisure-time activity as measured by the Behavioral Risk Factor Surveillance System and the National Health Interview Survey suggested that there has been no major downward shift in these patterns since 1986 (Caspersen \& Merritt, 1995; US Department of Health and Human Services, 1996). Indeed, there is evidence to suggest that there may have been an increase in moderate-intensity activity in those who have been initially sedentary (Stephens \& Caspersen, 1994). Although these trends could be taken to imply that certain sections of the population are responding to exhortations about the health benefits of exercise, they also need to be interpreted with caution. They may simply be masking an overall decline in physical activity and energy expenditure brought about by a concomitant reduction in occupational and other types of physical activity (Prentice \& Jebb, 1995). While it is notoriously difficult to measure accurately, all the indications are that work-related activity, even in manual occupations, has declined substantially over recent decades, and will probably continue to do so. Data from Finland suggest that the energy demands of work activity declined by $225 \mathrm{~kJ} / \mathrm{d}$ between 1982 and 1992 (Fogelholm et al. 1996). Thus, the nature, intensity and duration of non-occupational physical activity are likely to assume even greater importance in dictating the overall pattern of energy expenditure in the future. However, to date, the observed increases in leisuretime energy expenditure may not be sufficient to offset the decline in work-related energy expenditure.

Correlates of physical activity. The identification of correlates of physical activity is important for helping to shape public health policies and programmes to promote physical activity. Overall, most surveys reveal that: (1) men are more active than women; (2) activity levels decline with increasing age; (3) activity levels are consistently higher in those with higher education and income; (4) activity levels are inversely associated with adiposity.

Although most surveys have concluded that men are more active than women, it is important to emphasize that this difference is usually in the context of levels of participation in sports and other leisure activities, particularly those which are of vigorous intensity (Health Promotion Agency for Northern Ireland, 1994; Fentem \& Walker, 1995; Crespo et al. 1996; Jones et al. 1998; de Almeida et al. 1999). It is conceivable, however, that the disparity between the levels of physical activity of men and women that have been observed in those studies that omitted assessments of household activities may be more apparent than real, simply because the instruments used have better characterized the levels of physical activity of men (Cauley et al. 1987; Weller \& Corey, 1998; Ainsworth, 2000). More all-inclusive studies of physical activity demonstrated that it is not unusual for women to spend at least $2 \mathrm{~h} / \mathrm{d}$ in household and family-care tasks, compared with about $30 \mathrm{~min}$ for men (Richardson et al. 1994). An additional explanation for why the assessment of physical activity may have been more accurate in men than women is that recall and measurement error tend to be greater for light- and moderate-intensity activity compared with vigorous activity, which tends to be more time delineated (Richardson et al. 1994; DiPietro,
1995; Wareham \& Rennie, 1998). Consequently, if women perform activities that are mostly of lower intensity, errors in the estimation of their physical activity patterns could be magnified. Given the potential importance of household activities to the overall energy expenditure of women, it could be speculated that the proportion of women who meet current activity recommendations is probably greater than generally perceived. It may also be a possible explanation for the observation that, in contrast to men, physical activity in women is poorly associated with a reduced risk of mortality (Blair et al. 1993; Mensink et al. 1996).

Cross-sectional population surveys of physical activity are fairly consistent in reporting that inactivity increases with age in both men and women (Health Promotion Agency for Northern Ireland, 1994; Fentem \& Walker, 1995; Crespo et al. 1996; Jones et al. 1998; de Almeida et al. 1999). For example, data from the merged Allied Dunbar National Fitness Survey and Health Education Authority National Survey of Activity and Health show that the prevalence of inactivity increased from $15 \%$ in men and $25 \%$ in women aged 16-24 years, to approximately one-third in 45-65 year olds and $>50 \%$ in those aged $>65$ years (Fentem \& Walker, 1995). On the other hand, data from Canada and Finland suggest that patterns of physical activity may stabilize, or even increase, in the oldest age-groups relative to the nextyoungest age-group (Stephens \& Caspersen, 1994). In the Behavioral Risk Factor Surveillance System surveys in the USA, which have adjusted intensity of activity relative to age, the age-related decline is no longer present and, furthermore, there was evidence that activity levels increased in the oldest age-groups.

However, it is likely that the impact of increasing age on patterns of participation in physical activity may be more subtle and complex than appreciated. Data on the activity habits of a representative sample of approximately 1300 Irish adults suggest that men were twice as active women in occupational and leisure-time activities, while women were three times more active in household pursuits (Livingstone et al. 2001). Unfortunately, the downward shift in the occupational activity levels of the men with increasing age was not compensated for by increased participation in leisure or household activities. Indeed, leisure activities declined at an even greater rate. On the other hand, the activity levels of the women were more likely to be sustained over time, through substitution of reduced occupational activity with increased inputs into household pursuits. While increased reliance on technology may have substantially reduced the energy demands of household activity, nevertheless, the latter may still be an invaluable adjunct to overall energy expenditure in the face of declining demands of work activity.

A possible explanation for the observed decline in leisuretime activity with increasing age in the men in the Irish study might have been a shift in the type of recreational activities pursued. The amount of time spent in vigorous recreational activity decreased by $50 \%$ after age 36 years, suggesting that participation in higher-intensity recreational activities and team sports at a younger age was subsequently displaced in favour of less-physically-demanding recreational activity. However, the stability over time in the leisure-time activities in women, together with a less pronounced decline in 
vigorous activities (albeit from lower levels in the first place), suggest that they may have adopted more lifetime and individualized leisure pursuits from the outset, and were able to sustain these over time.

While these data are not necessarily representative of the time course of activity profiles in men and women, nevertheless, the data are used here to illustrate that the levels of physical activity in which individuals engage at any point in their lifespan reflect a complex interaction of biological, psychological and sociological factors. Thus, to generalize about age trends in physical activity solely on the basis of leisure-time activity may be misleading.

Levels of leisure-time physical activity are consistently higher in white Caucasian subjects and those with higher education and income (Sallis \& Hovell, 1990; Health Promotion Agency for Northern Ireland, 1994; Fentem \& Walker, 1995; Crespo et al. 1996, 1999; Jones et al. 1998; de Almeida et al. 1999). However, while education and income reflect socio-economic status, the latter tends to be less closely correlated with levels of physical activity (Livingstone et al. 2001). This variance may be attributed to the fact that since many surveys do not quantify occupational activity, there is likely to have been some misclassification of lower-income educated subjects who have physically-demanding jobs, and who are not interested in being active during their leisure time. For example, data from the 1990 National Health Interview Survey in the USA demonstrated that occupational activity was inversely associated with leisure-time activity and, in contrast to leisure-time activity, was higher in those with lower education and minority ethnic groups. It could be argued that if social class and educational status are proxy measures of a cluster of factors (knowledge, time, social support, perceived health status, access to facilities, neighbourhood safety), known to impact on levels of physical activity, it may be more instructive to directly assess the impact of these factors on levels of physical activity.

In conclusion, the balance of the epidemiological evidence suggests that there is a high prevalence of inactivity, but whether or not the level is increasing cannot be assessed from currently available data. Moreover, this conclusion must be tempered with the caution that many surveys have been limited to the measurement of leisure-time physical activity. Given the complex and multidimensional nature of physical activity, it seems most unlikely that recreational activity is an appropriate marker for overall activity patterns. Consequently, until more holistic assessments of physical activity can be obtained, it will be impossible to define the true extent of the problem of inactivity.

\section{Children}

At present there is a discernible feeling that children, and adolescents in particular, are less active and fit today than in the past. Indeed, the public perception of an increasingly sedentary way of life among children is even more widespread than it is for adults (Blair, 1992; Corbin \& Pangrazi, 1992). This perception, in turn, has prompted concerns about the impact of these declining levels of activity and fitness on the present and future health status of children.
However, despite the extensive literature charting the activity and fitness levels of children and adolescents, there is surprisingly little hard evidence to substantiate the popular perception that children have become habituated to sedentary living. The various literature reviews on the subject all concur that the available data on the levels of physical activity of children and adolescents can be distinguished more by its quantity than its quality (Cale \& Almond, 1992a; Sallis, 1993; Pate et al. 1994; Riddoch \& Boreham, 1995; Armstrong \& van Mechelen, 1998).

First, the results of different studies are often difficult to interpret and compare, because of the diversity of methodological approaches used to assess physical activity, differences in data analysis and reporting and the adoption of varying definitions for what constitutes an appropriate level of activity. It has been concluded that few, if any, studies fulfil all the criteria required to adequately characterize the status of children's physical activity (Riddoch \& Boreham, 1995). Second, much of the data are crosssectional and often drawn from small and non-random samples. Third, seasonal variability in patterns of physical activity is rarely accounted for. With these caveats in mind, a number of generalizations about activity levels can be made from the more robust data sets.

Population surveys: self-report. There are relatively few large-scale surveys of self-reported physical activity in children and adolescents. These surveys have been carried out in the USA (Ross \& Gilbert, 1985), Canada (Canada Fitness Survey, 1981); Northern Ireland (Riddoch et al. 1990) and Wales (Heartbeat Wales, 1986). To what extent these surveys, which were conducted 15-20 years ago, reflect current activity levels is debatable. In addition, while numerous small-scale surveys have been conducted, it is extremely difficult, for the reasons referred to earlier, to distil the information into a coherent account of physical activity behaviour. Overall, while the national surveys reveal considerable variability in activity habits, $60-70 \%$ of the children were engaged in physical activity of sufficient quantity and quality according to the activity criteria applied. Given the similarity in the results it is probable that there were no major differences, at that time, in the physical activity patterns between children in the USA and Canada and their European counterparts.

However more recent data from the UK National Diet and Nutrition Survey of children and adolescents (Gregory \& Lowe, 2000) indicated that $30 \%$ of the boys aged 7-10 years and $56 \%$ of the boys aged 15-18 years did not achieve the current recommendation of moderate physical activity for $1 \mathrm{~h}$ daily. The corresponding data for girls were 51 and $69 \%$. In contrast, data from the Youth Risk Behavior Survey, conducted periodically by the (US) Centers For Disease Control on the physical activity patterns of US adolescents, show that activity levels are quite high. Moreover, no consistent changes have been observed in these patterns of activity between 1991 and 1999 (Troiano et al. 2001). Given the problems of comparing cross-sectional data sets based on different survey methodologies, it is not possible to conclude if there has been a secular trend towards increased sedentariness. Moreover, self-report data must be interpreted with caution since they are vulnerable to misrepresentation, particularly exaggeration of the time spent in activity. 
Small-group studies: heart rate monitoring. In contrast to self-reported accounts of activity, studies that have objectively assessed physical activity patterns by HR monitoring report much lower levels of activity, albeit these studies are based on relatively small and often unrepresentative samples. However, the conclusions drawn from these studies critically depend on how the HR data are interpreted. Thus, if the accumulated time above HR thresholds for low, moderate and vigorous activity is accounted for, a very different picture about the prevalence of beneficial physical activity emerges from that in which the sustained amount of time above HR required to promote cardio-pulmonary fitness is the criterion (Riddoch \& Boreham, 1995). When the former criteria are adopted, there is considerable agreement between the results of different studies. Typically, children spend $37-111 \mathrm{~min} / \mathrm{d}$ in lowintensity activity, $15-40 \mathrm{~min} / \mathrm{d}$ in moderate-intensity activity and $4-22 \mathrm{~min} / \mathrm{d}$ in vigorous physical activity. In addition, there are no apparent gender differences in the amount of time engaged in low-intensity activity (Riddoch \& Boreham, 1995). However, HR data at the lower end of the HR range may not give a valid estimate of physical activity because of the increased likelihood of confounding by other factors. Thus, based on current activity guidelines for children and adolescents, it would be reasonable to conclude that most young people are active.

On the other hand, very different conclusions are drawn from HR data when more stringent cardiovascular fitness criteria are applied. The studies of Armstrong and colleagues (Armstrong, 1998) were primarily concerned with the number of 5, 10 and 20 min periods when HR was sustained at $>139$ and $>159$ beats $/ \mathrm{min}$. These studies demonstrated that $82 \%$ of the boys and $63 \%$ of the girls undertake only short periods $(5 \mathrm{~min})$ of activity with HR sustained at $>139$ beats/min, while $38 \%$ of the boys and $50 \%$ of the girls did not experience a single sustained $10 \mathrm{~min}$ period with HR > 139 beats/min. Of the children, $>75 \%$ did not experience a single sustained $20 \mathrm{~min}$ period with $\mathrm{HR}$ at $>159$ beats/min. Thus, when the data are analysed in this way it is impossible not to reach the opposite conclusion to that stated earlier. Clearly, these discrepancies highlight that, until consensus is reached about appropriate HR thresholds, widely varying estimates of the prevalence of beneficial physical activity will continue to be reported.

Small group studies: doubly-labelled water measurements. The use of DLW provides the most accurate quantitative assessments of TEE, but its application in physical activity epidemiology is limited by financial and technical constraints. In addition, no information is provided about the specific activities performed, or about the behavioural aspects of activity. TEE:BMR (measured or predicted), referred to as the physical activity level (PAL), is widely used to give an indirect measure of physical activity energy expenditure. Although PAL values include the energy costs of thermogenesis, most of the variance in PAL is attributable to variations in the energy turnover in physical activity.

There is now a fairly extensive database of DLW TEE measurements on children and adolescents, mostly from the USA and the UK. In young children (1-5 years) the PAL values typically lie within a relatively narrow range (1.40-1.50). A consistent observation in most of the DLW TEE studies is that children of $<7$ years appear to expend 20-30\% less energy than the level recommended by Food and Agriculture Organization/World Health Organization/United Nations University (1985). However, the recommendations for the age-group 1-10 years were based on published intake values, which had been inflated by $5 \%$ to accommodate 'a desirable level of physical activity'. The lower-than-expected energy cost of physical activity in young children is probably explained by the fact that, although they may be active, their activities are of low intensity and, typically, are not sustained over extended periods of time. Moreover, young children may spend substantial periods of time sleeping.

In older children (6-11 years) the PAL values are more variable, but most study mean values lie within the range $1.60-1.82$ and are broadly compatible with the suggested PAL for moderate-intensity (males, 1.75; females, 1.68) activity (Torun et al. 1996). On average, there are no gender differences in activity-related energy expenditure up until 11 years of age.

Unfortunately, there are relatively few DLW TEE data sets for adolescents (12-18 years). Most study mean PAL values for adolescent males lie within the range 1.65-2.0, which is compatible with the PAL range $(1.60-1.82)$ for light-to-moderate-intensity activity. The PAL values for adolescent females (1.60-1.85) show that they are meeting the PAL value (1.66) for a moderately-active lifestyle (Torun et al. 1996).

Thus, in contrast to the common perception that aspects of modern lifestyles are threatening the opportunity to be active, the available data for older children and adolescents suggest that, on average, they are moderately active. Whether these data are representative or not remains to be verified and, meanwhile, firm conclusions about activityrelated energy expenditure based on these limited data are not merited.

Patterns of participation in physical activity. One of the most pervasive findings of both cross-sectional and longitudinal studies of levels of physical activity in children and adolescents is that although activity levels decline in both males and females as they grow older, males are, on average, more active than females at all ages (Pate et al. 1994; Malina, 1995; Armstrong \& van Mechelen, 1998). Activity levels generally peak at about $12-14$ years and, although the annual rate of decline varies, it is much greater during adolescence than during adulthood (Caspersen et al. 2000).

However, examining only summary measures can obscure a variety of underlying patterns of change with age. Two rigorously-conducted longitudinal studies, the Amsterdam Growth and Health Study (van Mechelen et al. 2000) and the Cardiovascular Risk in Young Finns Study (Telema \& Yang, 2000), have provided unique insights into the natural timecourse of physical activity behaviour. Contrary to the general finding that the rate of decline in physical activity is greater in girls, both these studies observed a greater decline in most measures of physical activity in males. In the Amsterdam Growth and Health Study the overall energy expenditure score declined by $42 \%$ in males and $17 \%$ in females between 13 and 27 years of age, with the greatest decline taking place 
during the adolescent period. Moderate-intensity activity increased markedly in both males and females, at the expense of vigorous physical activity (males and females) and very vigorous physical activity (males). Overall, throughout the study the females were spending more time in moderateintensity activities than males. Time spent in non-organized sporting activities declined the most, with the most pronounced decrease occurring during the adolescent period in males.

Similarly, in the Cardiovascular Risk in Young Finns Study the physical activity index declined $55 \%$ in males and $20 \%$ in females from 12 to 27 years of age, with most of the decline occurring between 12 and 18 years in the males and 12 and 15 years in the females. However, the boys remained more active overall, because while the time they spent on physical activity decreased from $9.4 \mathrm{~h}$ at 13 years to $4.0 \mathrm{~h}$ at 18 years, the corresponding values for the girls were 5.9 and $3.7 \mathrm{~h}$. Overall, both studies demonstrated that girls engaged more regularly in moderate-intensity activity. However, compared with the Amsterdam Growth and Health Study, it appears that with increasing age, the males in the Cardiovascular Risk in Young Finns Study tended to split more and more into two groups, those who were totally sedentary and those who participated in fitness-related activity.

These two longitudinal studies present intriguing findings, and it remains to be verified if they are representative of the natural time-course of physical activity behaviour. Although the findings are somewhat at variance with the popular perceptions about gender differences in physical activity behaviour, they also serve to highlight the misconceptions that can arise by failing to fully characterize the different dimensions of physical activity in such studies. The undue emphasis that has been placed on sustained high-intensity activity in many of the HR and self-report studies of physical activity has probably favoured the physical activity profiles of boys. Differences between the genders may be greatly reduced when lower-intensity activity is also accounted for (Shephard, 1986). Thus, it is not unreasonable to speculate that the gender differences in levels of physical activity, which have been observed in many studies, may have been more apparent than real.

Indirect indices of physical activity. There is now substantial indirect evidence that children are increasingly being habituated to a sedentary lifestyle. In particular, the time devoted to television viewing and related media is one of the best proxy measures of inactivity. Approximately $75 \%$ of the 11-16-year-old UK children watch television for $2 \mathrm{~h} / \mathrm{d}$, with the remainder watching for $>4 \mathrm{~h} / \mathrm{d}$ (Health Education Authority, 1999). Data from the USA show that approximately one-quarter of US children watch television for $>4 \mathrm{~h} / \mathrm{d}$ and more than two-thirds watch television for at least $2 \mathrm{~h} / \mathrm{d}$ (Andersen et al. 1998). Related media such as computers also take up a large amount of time, with $10 \%$ of the 11-16 year olds playing computer games for $>10 \mathrm{~h} /$ week (Health Education Authority, 1999). Given that the majority of physical activity takes place outside school, common sense dictates that the sum of these passive leisure-time pursuits must be encroaching heavily on the time available for participation in active leisure-time physical activity.

At the same time, the opportunities to participate in regular physical activity in schools are being lost. Secondary schools in England and Wales now allocate less time to physical education than anywhere else in Europe, with the percentage of children spending $\geq 2 \mathrm{~h}$ /week in school sport decreasing from 46 in 1994 to 33 in 1999 (Sport England, 2000). The amount of time allocated to physical education in primary schools has also halved over the past 5 years (British Heart Foundation, 2000), and the situation in the USA is broadly similar (Kann et al. 1998).

Meanwhile, active transportation, particularly to and from school has decreased. In the UK National Diet and Nutrition Survey (Gregory \& Lowe, 2000), approximately half the children aged 4-10 years reported walking to school, with the remainder relying on motorized transport. However, by the age of 15-18 years the numbers of children who walked to school had decreased to approximately onethird. Another one-third travelled by bus and approximately one-quarter by car. Undoubtedly, the increasing pressures on children to be inactive, and particularly to spend more of their leisure time inside the home, are partly a result of parental concerns over children's safety. At the same time, however, it must be acknowledged that the desire to maximize efficiency in the face of increasing demands on everyone's time has undoubtedly led to many lost opportunities to be active throughout the day. Depending on the viewpoint taken, it seems that a physically-active lifestyle is fast becoming a luxury, or anathema, for many.

Are children active enough? The extent to which the activity levels of children are sufficient for promoting health is almost impossible to gauge at present because of the many contradictions and inconsistencies about this issue in the existing literature. A number of examples serve to illustrate the dilemma facing physical activity epidemiologists.

According to Blair et al. (1989), about $90 \%$ of the US children were deemed to be sufficiently active to achieve a health benefit when the criterion applied was achievement of an energy expenditure $>13 \mathrm{~kJ} / \mathrm{kg}$ per $\mathrm{d}$, and if even stricter criteria were used $(>17 \mathrm{~kJ} / \mathrm{kg}$ per d), $75 \%$ of the children achieved this standard. In contrast, when the threshold required for developing cardio-pulmonary fitness is adopted, children in a large number of studies were reported as having unacceptably low activity levels (Gilliam et al. 1981; MacConnie et al. 1982; Baranowski et al. 1987; Gilbey \& Gilbey, 1995; Armstrong, 1998). Those who have reviewed this issue also hold contrasting views. For example, in the opinion of Sallis (1993) the average child was sufficiently active to meet the adult recommendations for conditioning activities, an opinion not shared by Cale \& Almond (1992b,c), who concluded that primary and secondary schoolchildren experienced only low levels of activity. These examples serve to highlight one of the major obstacles in physical activity epidemiology at present, i.e. the interpretation of the levels of physical activity of children critically depend on the criterion levels of activity adopted and whether accumulated or sustained bouts of activity are included in the analysis.

The recent shift in emphasis to the value of accumulated activity of moderate-intensity activity for achieving a health benefit will impact markedly on future evaluations of children's activity levels. Applying this criterion, it seems likely that more children than were previously thought are meeting the minimum level of activity to achieve a health benefit. Indeed, when older data sets are re-visited, the 
previous negative interpretations of activity levels (based on sustained activity designed to promote cardio-pulmonary fitness) are no longer tenable in many cases (Sleap \& Tolfrey, 2001).

In conclusion, as stated earlier, data on the levels of physical activity of children can be distinguished more by their quantity than their quality. Consequently, no definitive conclusions are justified at present about either the levels of physical activity of children, or whether these levels are sufficient to maintain and promote health. In addition to the emphasis now placed on accumulated activity of moderate intensity, there is also the need to clearly identify the quantity and type of activity that is appropriate for promoting muscular strength, flexibility and bone health. At the same time, data on temporal trends in physical activity are virtually non-existent and unsubstantiated claims about declining levels of activity are not justified. If these are shown to be declining, it also needs to be established whether there is a general decline at all levels of physical activity, or whether the gap between sedentary and very active children is widening. In this context, generalizations about the levels of physical activity of children may be an uninformative basis for public health policy, given the undoubted variability in their patterns of activity. Priority needs to be given to identifying those children who are so inactive that their health may be compromised. Finally, in relation to obesity, the prevalence and value of low-tomoderate intensity needs to be established. Such activity may not conform to classical activity guidelines but it may markedly increase the overall energy expenditure of children if sustained for sufficiently lengthy periods.

Do activity levels track? Blair et al. (1989) hypothesized that an active child is more likely to become an active adult, and by implication, the carry-over effect of childhood physical activity could indirectly impact on adult health status. Conversely, if levels of physical activity exhibit stability over time, then children initially observed to be inactive relative to their peers would presumably become inactive adults who have an elevated risk of chronic disease mortality and morbidity.

Tracking may be defined as the maintenance of relative rank or position within an age-gender group over time, and where initial measurements predict later levels in the same individual. A high extent of tracking of physical activity behaviour suggests that the primary prevention of the chronic diseases that are associated with physical inactivity should be initiated through interventions that are directed at children from the outset. In addition to the health promotion implications, the phenomenon of tracking should increase understanding of the natural development of physical fitness and physical activity as health-related behaviours.

However, the data to support the contention that adult physical activity patterns are established during childhood are not convincing (Malina, 1996). Unfortunately, there are relatively few rigorously-conducted longitudinal studies of sufficient duration to permit an informed evaluation of the phenomenon (Raitakari et al. 1994; Twisk et al. 1997). Overall, these longitudinal studies reveal low-to-moderate inter-age tracking coefficients for estimates of physical activity during adolescence (13-18 years), from adolescence into adulthood (21-35 years), and across various ages during adulthood (Andersen \& Haraldsdottir, 1993; Raitakari et al. 1994; Frandin et al. 1995; Malina, 1996; Twisk et al. 1997). In fact, although tracking of physical inactivity has received far less attention, it appears that it may track better than physical activity (Raitakari et al. 1994). As pointed out by Dietz (1996), the adverse health consequences of inactivity may be just as important as the health benefits of vigorous activity. Thus, rather than being viewed simply as one end of a continuum of activity in tracking studies, accurate quantification and tracking of inactivity merits much more attention than hitherto.

Is it reasonable to expect that childhood and adolescent activity would strongly predict physical activity habits in adulthood? In the first place, the assessment of tracking is fraught with methodological and conceptual constraints. The levels of physical activity in which individuals engage at any point in their lifespan reflect a complex interaction of biological, psychological and sociological factors (Sallis \& Hovell, 1990). It is inconceivable, therefore, that the physical activity patterns of any individual, in terms of mode, frequency and intensity, will remain stable from childhood into adulthood.

Consequently, it is most unlikely that self-report methodology, the most commonly used tool for assessing tracking, could fully characterize secular changes in physical activity patterns. This position is particularly likely in those tracking studies in which overwhelming importance has been attached to a relatively narrow range of activities, most usually sports and other recreational activities. The retrospective estimation of physical activity is particularly problematic since the extent to which there is differential memory distortion and recall bias related to current physical activity is unknown. In prospective studies of tracking, the accuracy of self-reported physical activity may be compromised by cognitive limitations on reporting ability in young children, and by misrepresentation in older children, adolescents and adults. Clearly, the use of more objective methodology that avoids problems associated with recall or subjective responding is desirable. Only one study to date has investigated the phenomenon of tracking using HR assessments of physical activity (Pate et al. 1996). Although physical activity was measured for a limited period of 3 years, with only two to four observations per year, the very high tracking coefficient provided strong evidence that physical activity tends to remain stable in early childhood. However, the high correlation may be due as much to the close proximity of the measurements (Malina, 1996) as it is to the objective measurement of physical activity.

Perhaps one of the most obvious reasons why physical activity behaviour could not be expected to exhibit better stability over time is due to the very well-documented phenomenon of an age-related decline in physical activity (Sallis, 2000). Age is inversely associated with physical activity in studies of children (Sallis, 2000), children and adolescents (King \& Coles, 1992), and adults (Caspersen et al. 1994), and although the phenomenon is well accepted, it is not well understood. Longitudinal studies have demonstrated that the decline is steepest between the ages of 13 and 18 years (Telema \& Yang, 2000; van Mechelen et al. 2000) and is mostly attributable to a decrease in nonorganized sporting activities and vigorous physical activity 
(van Mechelen et al. 2000). However, in the absence of comparable data on young children, it is not known if the marked erosion in physical activity patterns during adolescence is unique, or whether it is pervasive throughout the whole of childhood and adolescence. Although less pronounced, activity patterns continue to decline up until the age of 30 years, after which cross-sectional data suggest a stabilization of activity patterns during middle life (Caspersen et al. 2000).

The remarkable consistency of the age-related decline in physical activity raises a number of questions as to the mechanisms underlying its decline. Psychological, sociological and physical factors undoubtedly help to explain this decline, but not totally. The age-related decrease in physical activity has also been observed in many animal species and strongly supports the contention that there exists a primary biological explanation for the trend (Ingram, 2000). A probable mechanism is the dopamine neurotransmitter system, which is responsible for regulating the motivation for motion (Ingram, 2000). Thus, while the age-associated decline in levels of physical activity is often viewed with dismay, it is to be partly expected, and is not necessarily problematic unless the decline is very pronounced. In the context of tracking, the issue that should be addressed is how the amount or timing of a decline in physical activity during childhood and adolescence influences later activity.

In conclusion, there is at present very little evidence to support the belief that physically-active children and adolescents will become active adults. It may be that it is the experiences related to participation in activity in childhood and adolescence, rather than the participation itself, which have a stronger influence on the predisposition to physical activity in adulthood (Engstrom, 1986; Taylor et al. 1999). This issue may be critical to a full understanding of the tracking phenomenon and merits further exploration.

\section{Physical inactivity and obesity: cause and/or consequence?}

\section{Adults}

The influence of regular physical activity on weight regulation is complex. Obesity and a sedentary lifestyle are two major interrelated health risks but, unfortunately, it is very difficult to tease out the extent of overlap, interactions and possible cause-and-effect associations between them in most epidemiological studies.

Several methodological issues constrain attempts to accurately determine the impact of physical activity on body weight and obesity: (1) measurement error with regard to the two key exposures, physical activity and dietary intake; (2) inappropriate time frame of the assessments; (3) effect modification by age and gender; (4) failure to adjust for important confounding variables (DiPietro, 1995).

The measurement of physical activity and food intake pose equally daunting challenges, given the tendency to over-report the former and under-report the latter (Prentice et al. 1986; Lichtman et al. 1992). Available techniques are unlikely to be sufficiently sensitive to the small short-term imbalances in each exposure, which ultimately lead to obesity. In particular, sedentary activity is not assessed well in most studies; rather, it is mostly inferred from an absence of active pursuits. An additional difficulty in establishing the relationship between weight gain and physical activity is that the activity levels of mildly-overweight and normalweight individuals may be virtually indistinguishable (Shah \& Jeffery, 1991). Consequently, as a result of these methodological issues, there is an enormous heterogeneity between studies, which limits interpretation of the data.

On balance, the ecological trends in populations suggest that declining amounts of physical activity have contributed markedly to the increasing prevalence of obesity (Prentice \& Jebb, 1995; Jebb \& Moore, 1999). Using data from a diversity of sources, Prentice \& Jebb (1995) have demonstrated that the rising prevalence of obesity has coincided with a fall in reported energy and fat intake, but with marked increases in two proxy measures of hypoactivity (time spent watching television and car ownership per household).

Cross-sectional associations between physical activity, or fitness, and body weight are stronger than those observed in prospective studies. An inverse association has been reported in many cross-sectional studies (for example, see Folsom et al. 1985; Voorrips et al. 1991; Slattery et al. 1992; DiPietro et al. 1993; Fogelholm et al. 1996; MartínezGonzález et al. 1999) and the baseline data in prospective studies (French et al. 1994). Many of these studies also report that high-intensity levels of self-reported physical activity are associated with consistently lower weight or body mass, but it is unclear if this association is simply due to better accuracy in reporting activities, which tend to be more structured and time delineated.

Data from approximately 19000 adults who reported they were trying to lose weight in the 1989 Behavioral Risk Factor Surveillance System Survey (DiPietro et al. 1993) suggest that the prevalence of obesity decreased markedly with increasing levels of activity. Among subjects in all agegroups, those who ran, jogged, performed aerobics or cycled weighed less than those who undertook no activity. Walking also produced marked weight loss in subjects after age 40 years. All differences were independent of height, race, education, smoking habit and energy restriction. However, this study shares the same limitation as many other crosssectional studies, which have compared differences in risk exposure between lean and obese, i.e. there is a high probability of post hoc changes in lifestyle (including physical activity behaviour) as a consequence of obesity.

The major limitation of any cross-sectional analysis is that the directionality of the physical activity-weight gain relationship cannot be determined. It is also impossible to assess the influence of weight status on activity level or, indeed, whether these associations are coincidental to genetic, behavioural or other factors that pre-dispose some individuals to leanness and a higher activity level, and others to obesity and inactivity.

In this context there are data to suggest that inactivity tends to cluster with other health behaviours such as less healthy dietary practices (Lytle et al. 1995; Simoes et al. 1995), cigarette smoking and alcohol use (Dannenberg et al. 1989; Raitakari et al. 1994; Lytle et al. 1995), which may have an adverse effect on both the quantity and distribution of body fat. Since smoking and alcohol increase visceral fat 
deposition (Troisi et al. 1991), and inactivity is associated with increased body fat, the net effect of the covariance of inactivity with other health behaviours is to increase the risk of morbidity and mortality associated with obesity.

Prospective studies provide the most robust data on the impact of physical activity on risk, or development, of excessive weight gain over time, because by definition the key exposures must precede the outcome. Unfortunately, there is a paucity of prospective data sets that measure the two key exposures: physical activity; dietary intake. These data sets can be broadly divided into those that have used single time-point measurements to predict subsequent weight change (Rissanen et al. 1991; Klesges et al. 1992; Lissner et al. 1997; Maffeis et al. 1998), and those that have examined the change in weight status relative to changes in the key exposures based on baseline and follow-up measurements (French et al. 1994; Coakley et al. 1998; Paeratakul et al. 1998; Twisk et al. 1998). Although the evidence is far from conclusive, most of these studies show some support for the role of physical activity in attenuating weight gain over time.

After adjustment for confounding factors, marked weight gain across baseline categories (frequently, occasionally or rarely) of self-reported leisure-time physical activity showed a modest dose-response relationship in both men and women (Rissanen et al. 1991). French et al. (1994) also observed that walking and high-intensity activities were independently associated with lower weight among men and women in the cross-sectional analysis at baseline, but that sustained activity of moderate-to-high intensity was a prerequisite for attenuated weight gain over time. However, in two studies these associations were seen only in women (Klesges et al. 1992; Paeratakul et al. 1998). In the women's study in Gothenberg, Sweden (Lissner et al. 1997), sedentary leisure activity appeared to be a risk factor only in those consuming a high-fat diet. In the Health Professionals Follow-up Study in the USA (Coakley et al. 1998), the prevalence of obesity in middle-aged men was lowest at follow-up among those who undertook relatively high levels of vigorous physical activity compared with their more sedentary counterparts. There was also a direct association between television and video cassette recorder viewing and body weight.

Further support for these observations is provided by those studies that have measured physical activity, but not diet, in relation to weight change. After 2 years of followup, higher baseline levels of physical activity and lower levels of television and video cassette recorder viewing remained independently related to a lower risk of becoming overweight in a large cohort of male health professionals (Ching et al. 1996). The Aerobics Center Longitudinal Study also demonstrated that improvements in fitness were associated with a reduction in risk of weight gain of $>5 \mathrm{~kg}$ over a period of 7-8 years (DiPietro et al. 1998). Finally, Williamson et al. (1993) demonstrated that low recreational activity levels in the National Health and Examination Follow-Up Study were associated with both risk of weight gain over a 10-year period as well as the prevalence of obesity at the start and end of the study. Of interest, however, no significant relationship was found between baseline levels of physical activity and subsequent weight gain among either men or women, suggesting that sedentary activity may be both a cause and a consequence of weight gain.

The totality of the evidence from these prospective studies, although inconclusive, suggests that physical activity or fitness plays more of a role in attenuating agerelated weight gain and preventing marked weight gain, rather than promoting weight loss where the effects are more modest (Wing, 1999). However, there is also a suggestion from both prospective (Coakley et al. 1998; DiPietro et al. 1998) and cross-sectional (Williams, 1997) studies that increased amounts of physical activity may be required to effectively stabilize body weight with increasing age.

Overall, firm conclusions from these prospective studies are precluded because of methodological flaws in the assessment of the risk exposures and the infrequency with which they are assessed, which may in turn have led to a substantial underestimate of the relative importance of levels of physical activity in weight regulation (Wong et al. 1999). What is indisputable, however, is that individuals who are concerned with overweight and obesity, and especially their prevention, should increase their levels of physical activity.

\section{Children}

Assessment of the relationship between levels of physical activity and adiposity in children and adolescents is even more constrained than it is in adults, because any possible relationship is heavily confounded during the pubertal years by normal physiological changes in body composition. Hence, it has been difficult to demonstrate anything more than a weak relationship between inactivity and increase in fatness in children (Bar-Or \& Baranowski, 1994).

Although some cross-sectional studies in adolescents have found an inverse relationship between physical activity and BMI or skinfold measurements (Tell et al. 1988; Macek et al. 1989; Kemper et al. 1990), other studies could not confirm the association (Andersen et al. 1989; Marti \& Vartiainen, 1989; Sallis et al. 1989). Two large crosssectional studies, which reported data on both activity and diet, noted only a weak association between lower levels of activity and higher levels of adiposity (Sunnegardh et al. 1986; Shannon et al. 1995), but in both studies confounding variables could not be fully excluded. Children of parents with lower levels of income and education were fatter and this outcome was also associated with television viewing and sedentary pursuits.

Using DLW estimates of TEE, a negative association between two indices of physical activity (TEE - BMR and PAL) and percentage body fat has been demonstrated in preschool children aged 1.5-4.5 years (Davies et al. 1995). Given that this population was not selected to be obese, the data suggest that either a decline in activity energy expenditure precedes the development of obesity, or accompanies it. In contrast, Goran et al. (1997) could not demonstrate any association between activity energy expenditure and body fatness, whereas time devoted to recreational activity, as assessed by questionnaire, was inversely related to fat mass. The authors suggested that the time devoted to physical activity, rather than activity energy expenditure per se, may be the most important factor in energy regulation. 
The outcome of prospective studies has also been inconsistent. Two studies have reported an inverse relationship between physical activity and indices of body fatness (Klesges et al. 1995; Moore et al. 1995). On the other hand, Aaron et al. (1992) could find no association between physical activity and weight gain in the Adolescent Injury Control Study, after controlling for confounding factors. Similarly, Beunen et al. (1992) reported no relationship between separate skinfold thickness and self-reported participation in sports in matched groups of active and less active Belgian adolescents. Unfortunately, no account was taken of activities other than sports activities in this study. Finally, Maffeis et al. (1998) found that physical activity and/or television viewing (as a proxy measure for inactivity) were unrelated to change in relative BMI in a 4-year longitudinal study.

To date, stronger relationships have been observed between patterns of sedentary living, most notably time spent watching television and related pursuits and obesity, than with physically-active pursuits. Most studies (Dietz \& Gortmaker, 1984, 1985; Tucker, 1986; Pate \& Ross, 1987; Wong et al. 1992; Gortmaker et al. 1996; Hernández et al. 1999; Crespo et al. 2001), but not all (Robinson et al. 1993; Wolf et al. 1993; Robinson \& Killen, 1995), have found that the amount of time children and adolescents spend watching television was associated with increased obesity, less physical activity and lower physical fitness. Among the possible reasons cited for the failure to demonstrate an association are unrepresentative sampling and inability to correctly characterize television viewing behaviour. It has also been noted that in younger children aged 3-4 years (DuRant et al. 1994), those who watched more television were less physically active, but this lower activity did not manifest itself in greater adiposity. However, this outcome may simply be a result of the fact that the impact of television viewing on adiposity is insidious, but ultimately it can lead to obesity. This possibility is confirmed by the fact that stronger relationships between watching television and obesity have been found in older (12-17 years) children compared with younger (6-11 years) children (Dietz \& Gortmaker, 1985).

The most compelling evidence for the existence of a doseresponse relationship between the prevalence of obesity and number of hours of television viewing is provided by the longitudinal study (1986-1990) of Gortmaker et al. (1996) on a representative sample of 746 US adolescents. After adjusting for potential confounding factors, the relative risk of obesity was $5 \cdot 3$ times greater for approximately one-third of the adolescents who watched television for $>5 \mathrm{~h} / \mathrm{d}$, compared with those who watched television for $0-2 \mathrm{~h} / \mathrm{d}$. Over the 4 years the prevalence and incidence of obesity were positively associated with the time spent watching television, while remission was negatively associated, and by the same order of magnitude. The authors proposed that efforts to reduce the time spent in television viewing may be effective in preventing some of the incidence of obesity and there is some experimental support for this viewpoint (Epstein et al.1995, 2000). It should also be noted that not only is a reduced energy expenditure associated with television viewing (Dietz et al. 1994), but the increased opportunities for hyperphagia while doing so may be as important as reduced activity in the genesis of obesity. This explanation is consistent with other observations that suggest covariance between sedentary behaviour and other behaviours such as smoking, fat intake and alcohol consumption (Escobedo et al. 1993; Lytle et al. 1995).

On balance, there is clear evidence that low levels of physical activity are associated with an increased risk of weight gain and obesity, but causality remains to be established. Surprisingly, the potential interactions between physical activity and dietary intake behaviours have largely been ignored in epidemiological studies. From a policy standpoint, a number of issues should also be resolved. It would be particularly useful to know whether increasing the proportion of active individuals (and decreasing the proportion of inactive individuals) in the population would reduce the prevalence of obesity, and/or the incidence of chronic diseases associated with obesity, as well as those associated with a sedentary status. It could also be queried whether reducing the proportion of obese individuals would bring about a more active population.

\section{Conclusion}

Advice aimed at promoting physical activity should be based on actual evidence concerning how individuals spend their time. However, given the conceptual complexities and measurement difficulties associated with physical activity, few researchers would argue that it is difficult to detect trends and draw meaningful conclusions from the existing evidence. Future research should focus on refining physical activity assessment methodology to make it more sensitive to the different dimensions and contexts of physical activity in different groups. Activity recommendations now emphasize the importance of accumulated activity of moderate intensity. Consequently, future surveys will need to incorporate assessment of activities ranging from occupation, household tasks, other activities of daily living and transportation in order to capture all activity of moderate intensity as well as vigorous intensity. In the context of children's activity patterns a more ecological perspective, with emphasis on objective assessment of total activity in natural settings, should be prioritized. Research is also required to develop valid rather than proxy measures of sedentary behaviours in both children and adults. In summary, while all the indications are that the activity levels of both children and adults are under threat, the challenge is to find compelling evidence in support of this.

\section{References}

Aaron DJ, Dearwater SR \& Kriska AM (1992) Are activity and/or fitness related to weight gain in adolescents? Data from the AIC Study. Medicine and Science in Sports and Exercise 24, S124.

Ainsworth BE (2000) Challenges in measuring physical activity in women. Exercise and Sport Sciences Reviews 28, 93-96.

Albanes D, Blair A \& Taylor PR (1989) Physical activity and risk of cancer in the NHANES I population. American Journal of Public Health 79, 744-750.

Alpert BS \& Wilmore JH (1994) Physical activity and blood pressure in adolescents. Pediatric Exercise Science 6, 361-380.

American College of Sports Medicine (1978) The recommended quantity and quality of exercise for developing and maintaining 
fitness in healthy adults. Medicine and Science in Sports and Exercise 10, vii- $\mathrm{x}$.

American College of Sports Medicine (1990) The recommended quality and quantity of exercise for developing and maintaining fitness in healthy adults. Medicine and Science in Sports and Exercise 22, 265-274.

Andersen LB \& Haraldsdottir J (1993) Tracking of cardiovascular disease risk factors including maximal oxygen uptake and physical activity from late teenage to adulthood. An 8-year follow-up study. Journal of International Medicine 234, 309-315.

Andersen LB, Henckel P \& Saltin B (1989) Risk factors for cardiovascular disease in 16-19-year-old teenagers. Journal of International Medicine 225, 157-163.

Andersen RE, Crespo CJ, Bartlett SJ, Cheskin LJ \& Pratt M (1998) Relationship of physical activity and television watching with body weight and level of fatness among children. Journal of the American Medical Association 279, 938-942.

Armstrong N (1998) Young people's physical activity patterns as assessed by heart rate monitoring. Journal of Sports Science 16, S9-S16.

Armstrong N \& Bray S (1991) Physical activity patterns defined by continuous heart rate monitoring. Archives of Disease in Childhood 66, 245-247.

Armstrong N \& Simons-Morton B (1994) Physical activity and blood lipids in adolescents. Pediatric Exercise Science 6, 381-405.

Armstrong N \& van Mechelen W (1998) Are young people fit and active? In Young and Active, pp. 69-97 [SJH Biddle, JF Sallis and NC Cavill, editors]. London: Health Education Authority.

Armstrong N \& Welsman JR (1997) Young People and Physical Activity. Oxford: Oxford University Press.

Arroll B \& Beaglehole R (1992) Does physical activity lower blood pressure? A critical review of the clinical trials. Journal of Clinical Epidemiology 45, 439-447.

Bailey DA, Faulkner RA \& McKay HA (1996) Growth, physical activity and bone mineral acquisition. Exercise and Sports Science Reviews 24, 233-266.

Bailey DA \& Martin AD (1994) Physical activity and skeletal health in adolescents. Pediatric Exercise Science 6, 330-347.

Bailey RC, Olson J, Pepper SL, Porszasz J, Barstow TJ \& Cooper DM (1995) The level and tempo of children's physical activities: an observational study. Medicine and Science in Sports and Exercise 27, 1033-1041.

Baranowski T, Bouchard C, Bar-Or O, Bricker T, Heath G, Kimm SYS, Malina R, Obarzanek E, Pate R, Strong WB, Truman B \& Washington R (1992) Assessment, prevalence, and cardiovascular benefits of physical activity and fitness in youth. Medicine and Science in Sports and Exercise 24, Suppl., S237-S247.

Baranowski T, Hooks P, Tsong Y, Cieslik C \& Nader PR (1987) Aerobic physical activity among third- to sixth-grade children. Journal of Developmental and Behavioral Pediatrics 8, 203-206.

Baranowski T \& Simons-Morton BG (1991) Dietary and physical activity assessment in school-aged children: measurement issues. Journal of School Health 61, 195-197.

Barnard RJ \& Wen SJ (1994) Exercise and diet in the prevention and control of the metabolic syndrome. Sports Medicine 18, 218-228.

Bar-Or O (1994) Childhood and adolescent physical activity and fitness and adult risk profile. In Health and Fitness through Physical Education, pp. 931-942 [RR Pate and RC Hohn, editors]. Champaign, IL: Human Kinetics.

Bar-Or O \& Baranowski T (1994) Physical activity, adiposity and obesity among adolescents. Pediatric Exercise Science 6, 348-360.

Berlin JA \& Colditz GA (1990) A meta-analysis of physical activity in the prevention of coronary heart disease. American Journal of Epidemiology 132, 612-627.
Beunen GP, Malina RM, Renson R, Simons J, Ostyn M \& Lefevre J (1992) Physical activity and growth, maturation and performance: A longitudinal study. Medicine and Science in Sports and Exercise 24, 576-585.

Biddle SJH, Sallis JF \& Cavill NA (editors) (1998) Young and Active? Young People and Health Enhancing Physical Activity: Evidence and Implications. London: Health Education Authority.

Blair SN (1992) Are American children and youth fit? The need for better data. Research Quarterly for Exercise and Sport 63, $120-123$.

Blair SN, Clark DG, Cureton KJ \& Powell KE (1989) Exercise and fitness in childhood: implications for a lifetime of health. In Perspectives in Exercise Science and Sports Medicine, pp. 401-430 [CV Gisolfi and DR Lamb, editors]. New York: McGraw-Hill.

Blair SN \& Connelly JC (1996) How much physical activity should we do? The case for moderate amounts and intensities of physical activity. Research Quarterly for Exercise and Sport 67, 193-205.

Blair SN, Kohl HW \& Barlow CE (1993) Physical activity, physical fitness, and all-cause mortality in women: do women need to be active? Journal of the American College of Nutrition 12, 368-371.

Blair SN, Kohl HW, Gordon NF \& Paffenbarger RS (1992) How much physical activity is good for health? Annual Review of Public Health 13, 99-126.

Boreham CA, Twisk J, Savage MJ, Cran GW \& Strain JJ (1997) Physical activity, sports participation, and risk factors in adolescents. Medicine and Science in Sports and Exercise 29, 788-793.

Borer KT (1995) The effects of exercise on growth. Sports Medicine 20, 375-397.

Bouten CVC, Verboeket-van de Venne WPHG, Westerterp KR, Verduin M \& Janssen JD (1996) Daily physical activity assessment: comparison between movement registration and doubly labeled water. Journal of Applied Physiology 81, 1019-1026.

British Heart Foundation (2000) Couch Kids - The Growing Epidemic. London: British Heart Foundation.

Cale L \& Almond L (1992a) Children's activity levels: a review of studies conducted on British children. Physical Education Review 15, 111-118.

Cale L \& Almond L (1992b) Physical activity levels of young children: a review of the evidence. Health Education Journal $\mathbf{5 1}$ 94-99.

Cale L \& Almond L (1992c) Physical activity levels of secondaryaged children: a review. Health Education Journal 51, 192-197.

Cale L \& Harris J (1993) Exercise recommendations for children and young people. Physical Education Review 16, 89-102.

Calfas KJ \& Taylor C (1994) Effects of physical activity on psychological variables in adolescents. Pediatric Exercise Science 6, 406-423.

Canada Fitness Survey (1981) Canadian Youth and Physical Activity. Ottawa: Canada Fitness Survey.

Caspersen CJ (1989) Physical activity epidemiology: concepts, methods, and applications to exercise science. Exercise and Sports Science Reviews 17, 423-473.

Caspersen CJ \& Merritt RK (1995) Physical activity trends among 26 states, 1986-1990. Medicine and Science in Sports and Exercise 27, 713-720.

Caspersen CJ, Merritt RK \& Stephens T (1994) International activity patterns: a methodological perspective. In Advances in Exercise Adherence, pp 73-110 [RK Dishman, editor]. Champaign, IL: Human Kinetics.

Caspersen CJ, Nixon PA \& DuRant RH (1998) Physical activity epidemiology applied to children and adolescents. Exercise and Sports Science Reviews 26, 341-403. 
Caspersen CJ, Pereira MA \& Curran KM (2000) Changes in physical activity patterns in the United States, by sex and crosssectional age. Medicine and Science in Sports and Exercise 32, $1601-1609$

Caspersen CJ, Powell KE \& Christenson GM (1985) Physical activity, exercise, and physical fitness: definitions and distinctions for health-related research. Public Health Reports 100, 126-131.

Cauley JA, LaPorte RE, Sandler RB, Schramm MM \& Kriska AM (1987) Comparison of methods to measure physical activity in postmenopausal women. American Journal of Clinical Nutrition 45, 14-22.

Centers for Disease Control (1995) Assessing Health Risks in America. The Behavioral Risk Factor Surveillance System (BRFSS) at a Glance. Atlanta, GA: Centers for Disease Control and Prevention.

Chilibeck PD, Sale DG \& Webber CE (1995) Exercise and bone mineral density. Sports Medicine 19, 103-122.

Ching PLYH, Willett WC, Rimm EB, Colditz GA, Gortmaker SL \& Stampfer MJ (1996) Activity level and risk of overweight in male health professionals. American Journal of Public Health 86, 25-30.

Chinn S \& Rona RJ (2001) Prevalence and trends in overweight and obesity in three cross sectional studies in British children 1974-94. British Medical Journal 322, 24-26.

Coakley EH, Rimm EB, Colditz G, Kawachi I \& Willett W (1998) Predictors of weight change in men: Results from The Health Professionals Follow-Up Study. International Journal of Obesity 22, 89-96.

Corbin CB \& Pangrazi RP (1992) Are American children and youth fit? Research Quarterly for Exercise and Sport 63, 96-106.

Crespo CJ, Ainsworth BE, Keteyian SJ, Heath GW \& Smit E (1999) Prevalence of physical inactivity and its relation to social class in US adults: results from the Third National Health and Nutrition Examination Survey, 1988-1994. Medicine and Science in Sports and Exercise 31, 1821-1827.

Crespo CJ, Keteyian SJ, Heath GW \& Sempos CT (1996) Leisuretime physical activity among US adults. Results from the Third National Health and Nutrition Examination Survey. Archives of Internal Medicine 156, 93-98.

Crespo CJ, Smit E, Troiano RP, Bartlett SJ, Macera CA \& Andersen RE (2001) Television watching, energy intake, and obesity in US children: results from the third National Health and Nutrition Examination Survey, 1988-1994. Archives of Pediatric and Adolescent Medicine 155, 360-365.

Cummings SR, Kelsey JL, Nevitt MC \& O’Dowd KJ (1985) Epidemiology of osteoporosis and osteoporotic fractures. Epidemiological Reviews 7, 178-208.

Danforth JS, Allen KD, Fitterling JM, Danforth JA, Farrar D, Brown M \& Drabman RS (1990) Exercise as a treatment for hypertension in low socioeconomic status black children. Journal of Consulting Clinical Psychology 58, 237-239.

Dannenberg AL, Keller JB, Wilson PWF \& Castelli WP (1989) Leisure time physical activity in the Framingham offspring study. Description, seasonal variation, and risk factor correlates. American Journal of Epidemiology 129, 76-88.

Davies PSW, Gregory J \& White A (1995) Physical activity and body fatness in pre-school children. International Journal of Obesity 19, 6-10.

de Almeida MDV, Graca P, Afonso C, D'Amicis A, Lappalainen R \& Damkjaer S (1999) Physical activity levels and body weight in a nationally representative sample in the European Union. Public Health Nutrition 2, 105-113.

DeBusk RF, Stenestrand U, Sheehan M \& Haskell WL (1990) Training effects of long versus short bouts of exercise in healthy subjects. American Journal of Cardiology 65, 1010-1013.
Department of Health and Social Services (1996) Strategy Statement on Physical Activity. London: Department of Health.

Dietz WH (1996) The role of lifestyle in health: the epidemiology and consequences of inactivity. Proceedings of the Nutrition Society 55, 829-840.

Dietz WH, Bandini LG, Morelli JA, Peers KF \& Ching PLYH (1994) Effect of sedentary activities on resting metabolic rate. American Journal of Clinical Nutrition 59, 556-559.

Dietz WH \& Gortmaker SL (1984) Factors within the physical environment associated with childhood obesity. American Journal of Clinical Nutrition 39, 619-624.

Dietz WH \& Gortmaker SL (1985) Do we fatten our children at the TV set? Obesity and television viewing in children and adolescents. Pediatrics 75, 807-812.

DiPietro L (1995) Physical activity, body weight, and adiposity: an epidemiologic perspective. Exercise and Sports Science Reviews 23, 275-303.

DiPietro L, Kohl HW III, Barlow CE \& Blair SN (1998) Improvements in cardiovascular fitness attenuate age-related weight gain in healthy men and women: The Aerobics Center Longitudinal Study. International Journal of Obesity 22, 55-62.

DiPietro L, Williamson DF, Caspersen CJ \& Eaker E (1993) The descriptive epidemiology of selected physical activities and body weight among adults trying to lose weight: the Behavioral Risk Factor Surveillance System Survey. International Journal of Obesity 17, 69-76.

DuRant RH, Baranowski T, Johnson M \& Thompson WO (1994) The relationship among television watching, physical activity, and body composition of young children. Pediatrics 94, 449-455.

Ebisu T (1985) Splitting the distance of endurance running: on cardiovascular endurance and blood lipids. Japanese Journal of Physical Education 30, 37-43.

Ekeland U, Sjöström M, Yngve A \& Nilsson A (2000) Total daily energy expenditure and pattern of physical activity measured by minute-by-minute heart rate monitoring in 14-15 year old Swedish adolescents. European Journal of Clinical Nutrition 54, 195-202.

Ekelund U, Sjöström M, Yngve A, Poortvliet E, Nilsson A, Froberg K, Wedderkopp N \& Westerterp K (2001) Physical activity assessed by activity monitor and doubly labeled water in children. Medicine and Science in Sports and Exercise 33, 275-281.

Engstom L-M (1986) The process of socialisation into keep-fit activities. Scandinavian Journal of Sports Science 8, 89-97.

Epstein LH, Paluch RA, Gordy CC \& Dorn J (2000) Decreasing sedentary behaviors in treating pediatric obesity. Archives of Pediatric and Adolescent Medicine 154, 220-226.

Epstein LH, Valoski AM, Vara LS, McCurley J, Wisniewski L, Kalarchian MA, Klein KR \& Shrager LR (1995) Effects of decreasing sedentary behavior and increasing activity on weight change in obese children. Health Psychology 14, 109-115.

Escobedo LG, Marcus SE, Holtzman D \& Giovino GA (1993) Sports participation, age at smoking initiation, and risk of smoking among US high school students. Journal of the American Medical Association 269, 1391-1395.

Eston RG, Rowlands AV \& Ingledew DK (1998) Validity of heart rate, pedometry, and accelerometry for predicting the energy cost of children's activities. Journal of Applied Physiology 84, 362-371.

Fentem P \& Walker A (1995) Setting targets for England: Challenging, measurable and achievable. In Moving On: International Perspectives on Promoting Physical Activity, pp. 58-76 [AJ Killoran, P Fentem and C Caspersen, editors]. London: Health Education Authority. 
Fogelholm M, Mannisto S, Vartiainen E \& Pietinen P (1996) Determinants of energy balance and overweight in Finland 1982 and 1992. International Journal of Obesity 20, 1097-1104.

Folsom AR, Caspersen CJ, Taylor HL, Jacobs DR, Luepker RV, Gomez-Marin O \& Gillum RF (1985) Leisure time physical activity and its relationship to coronary risk factors in a population-based sample. The Minnesota Heart Survey. American Journal of Epidemiology 121, 570-579.

Food and Agriculture Organization/World Health Organization/ United Nations University (1985) Energy and Protein Requirements. WHO Technical Report Series no. 724. Geneva: WHO.

Frandin K, Mellstrom D, Sundh V \& Grimby G (1995) A lifespan perspective on patterns of physical activity and functional performance at the age of 76. Gerontology 41, 109-120.

French SA, Jeffery RW, Forster JL, McGovern PG, Kelder SH \& Baxter JE (1994) Predictors of weight change over two years among a population of working adults: the Healthy Worker Project. International Journal of Obesity 18, 145-154.

Gilbey H \& Gilbey M (1995) The physical activity of Singapore primary school children as estimated by heart rate monitoring. Pediatric Exercise Science 7, 26-35.

Gilliam TB, Freedson PS, Geenen DL \& Shahraray B (1981) Physical activity patterns determined by heart rate monitoring in 6-7 year-old children. Medicine and Science in Sports and Exercise 13, 65-67.

Goran MI, Hunter G, Nagy TR \& Johnson R (1997) Physical activity related energy expenditure and fat mass in young children. International Journal of Obesity 21, 171-178.

Gordon J \& Grant G (1997) How We Feel. London: Jessica Kingsley Publishers.

Gortmaker SL, Must A, Sobol AM, Peterson K, Colditz GA \& Dietz WH (1996) Television viewing as a cause of increasing obesity among children in the United States, 1986-1990. Archives of Paediatric and Adolescent Medicine 150, 356-362.

Gregory J \& Lowe S (2000) National Diet and Nutrition Survey: Young People Aged 4 to 18 Years. London: The Stationery Office.

Gruber JJ (1986) Physical activity and self-esteem development in children: a meta-analysis. In Effects of Physical Activity on Children, pp 330-348 [G Stull and H Eckert, editors]. Champaign, IL: Human Kinetics.

Hagberg JM, Goldring D, Ehsani AA, Heath GW, Hernandez A, Schechtman K \& Holloszy JO (1983) Effect of exercise training on the blood pressure and hemodynamic features of hypertensive adolescents. American Journal of Cardiology 52, 763-768.

Hansen HS, Froberg K, Hyldebrandt N \& Nielsen JR (1991) A controlled study of eight months of physical training and reduction of blood pressure in children: the Odense schoolchild study. British Medical Journal 303, 682-685.

Harter S (1988) Developmental processes in the construction of the self. In Integrative Processes and Early Socialization: Early to Middle Childhood, pp. 45-78 [TD Yawkey and JE Johnson, editors]. Hillsdale, NJ: Erlbaum.

Haskell WL (1994) Health consequences of physical activity: understanding and challenges regarding dose-response. Medicine and Science in Sports and Exercise 26, 649-660.

Health Education Authority (1999) Young People and Health: Health Behaviour in School-aged Children. A Report of the 1997 Findings. London: Health Education Authority.

Health Promotion Agency for Northern Ireland (1994) The Northern Ireland Health and Activity Survey: Main Findings. Belfast: H. M. Stationery Office.

Heartbeat Wales (1986) Welsh Youth Health Survey 1986. Heartbeat Report no. 5. Cardiff: Heartbeat Wales.
Helmrich SP, Ragland DR, Leung RW \& Paffenbarger RS (1991) Physical activity and reduced occurrence of noninsulin-dependent diabetes mellitus. New England Journal of Medicine 325, 147-152.

Hernández B, Gortmaker SL, Colditz GA, Peterson KE, Laird NM \& Parra-Cabrera S (1999) Association of obesity with physical activity, television programs and other forms of video viewing among children in Mexico city. International Journal of Obesity 23, 845-854.

Hopkins WG, Wilson NC \& Russell DG (1991) Validation of the physical activity instrument for the Life in New Zealand national survey. American Journal of Epidemiology 133, 73-82.

Ingram DK (2000) Age-related decline in physical activity: generalization to nonhumans. Medicine and Science in Sports and Exercise 32, 1623-1629.

Jacobs DR, Ainsworth BE, Hartman TL \& Leon AS (1993) A simultaneous evaluation of 10 commonly used physical activity questionnaires. Medicine and Science in Sports and Exercise $\mathbf{2 5}$, 81-91.

Janz KF (1994) Validation of the CSA accelerometer for assessing children's physical activity. Medicine and Science in Sports and Exercise 26, 369-375.

Jebb SA \& Moore MS (1999) Contribution of a sedentary lifestyle and inactivity to the etiology of overweight and obesity: current evidence and research issues. Medicine and Science in Sports and Exercise 31, Suppl., S534-S541.

Jennings G, Nelson L, Nestel P, Esler M, Korner P, Burton D \& Bazelmans J (1986) The effects of changes in physical activity on major cardiovascular risk factors, hemodynamics, sympathetic function, and glucose utilization in man: a controlled study of four levels of activity. Circulation 73, 30-40.

Johnson RK, Russ J \& Goran MI (1998) Physical activity related energy expenditure in children by doubly labeled water as compared with the Caltrac accelerometer. International Journal of Obesity 22, 1046-1052.

Jones DA, Ainsworth BE, Croft JB, Macera CA, Lloyd EE \& Yusuf HR (1998) Moderate leisure-time physical activity. Who is meeting the public health recommendations? A national crosssectional study. Archives of Family Medicine 7, 285-289.

Kann L, Kinchen SA \& Williams BI (1998) Youth risk behaviour surveillance - United States, 1997. Morbidity and Mortality Weekly Report CDC Surveillance Summaries 47, 1-32.

Kemper HCG, Nels J, Verschuur R \& Storm-van Essen L (1990) Tracking of health and risk indicators of cardiovascular disease from teenager to adult: Amsterdam Growth and Health Study. Preventive Medicine 19, 642-655.

Kesaniemi YA, Danforth E, Jensen MD, Kopelman PG, Lefebvre P \& Reeder BA (2001) Dose-response issues concerning physical activity and health: an evidence-based symposium. Medicine and Science in Sports and Exercise 33, Suppl. 6, S351-S358.

King AJC \& Coles B (1992) The Health of Canada's Youth: Views and Behaviours of 11-13, and 15-Year-olds from 11 Countries. Ottawa: Minister of National Health and Welfare.

Klesges RC, Klesges LM, Eck LH \& Shelton ML (1995) A longitudinal analysis of accelerated weight gain in preschool children. Pediatrics 95, 126-130.

Klesges RC, Klesges LM, Haddock CK \& Eck LH (1992) A longitudinal analysis of the impact of dietary intake and physical activity on weight change in adults. American Journal of Clinical Nutrition 55, 818-822.

Lee I, Paffenbarger RS \& Hseih C (1991) Physical activity and risk of developing colorectal cancer among college alumni. Journal of the National Cancer Institute 83, 1324-1329.

Leon AS, Connett J, Jacobs DR \& Rauramaa R (1987) Leisure-time physical activity levels and risk of coronary heart disease and death. The Multiple Risk Factor Intervention Trial. Journal of the American Medical Association 258, 2388-2395. 
Lichtman SW, Pisarska K, Berman ER, Pestone M, Dowling H, Offenbacher E, Weisel H, Heshka S, Matthews DE \& Heymsfield SB (1992) Discrepancy between self-reported and actual caloric intake and exercise in obese subjects. New England Journal of Medicine 327, 1893-1898.

Lissner L, Heitmann BL \& Bengtsson C (1997) Low-fat diets may prevent weight gain in sedentary women: prospective observations from the population study of women in Gothenburg, Sweden. Obesity Research 5, 43-48.

Livingstone B (2000) Epidemiology of childhood obesity in Europe. European Journal of Pediatrics 159, Suppl.1, S14-S34.

Livingstone MBE (1994) Energy expenditure and physical activity in relation to fitness in children. Proceedings of the Nutrition Society 53, 207-221.

Livingstone MBE (1997) Heart-rate monitoring: the answer for assessing energy expenditure and physical activity in population studies? British Journal of Nutrition 78, 869-871.

Livingstone MBE, Coward WA, Prentice AM, Davies PSW, Strain JJ, McKenna PG, Mahoney CA, White JA, Stewart CM \& Kerr M-JJ (1992) Daily energy expenditure in free-living children: comparison of heart rate monitoring with the doubly labeled water $\left({ }^{2} \mathrm{H}_{2}{ }^{18} \mathrm{O}\right)$ method. American Journal of Clinical Nutrition 56, 343-352.

Livingstone MBE, Prentice AM, Coward WA, Ceesay SM, Strain JJ, McKenna PG, Nevin GB, Barker ME \& Hickey RJ (1990) Simultaneous measurement of free-living energy expenditure by the doubly-labeled water $\left({ }^{2} \mathrm{H}_{2}{ }^{18} \mathrm{O}\right)$ method and heart-rate monitoring. American Journal of Clinical Nutrition 52, 59-65.

Livingstone MBE, Robson PJ, McCarthy S, Kiely M, Harrington K, Browne P, Galvin M, Wareham NJ \& Rennie KL (2001) Physical activity patterns in a nationally representative sample of adults in Ireland. Public Health Nutrition 4, 1107-1116.

Lovelady CA, Meredith CN, McCrory MA, Nommsen LA, Joseph LJ \& Dewey KG (1993) Energy expenditure in lactating women: a comparison of doubly labeled with heart-rate-monitoring methods. American Journal of Clinical Nutrition 57, 512-518.

Lytle LA, Kelder SH, Perry CL \& Klepp K-I (1995) Covariance of adolescent health behaviors: the Class of 1989 Study. Health Education Research 10, 133-146.

MacConnie SE, Gilliam TB, Geenen DL \& Pels AE (1982) Daily physical activity patterns in prepubertal children involved in a vigorous exercise program. International Journal of Sports Medicine 3, 202-207.

Macek M, Bell D, Rutenfranz J, Vavra J, Masopust J, Neidhart B \& Schmidt KH (1989) A comparison of coronary risk factors in groups of trained and untrained adolescents. European Journal of Applied Physiology 58, 577-582.

Macera CA \& Pratt M (2000) Public health surveillance of physical activity. Research Quarterly for Exercise and Sport 71, S97-S103.

Maffeis C, Talamini G \& Tatò L (1998) Influence of diet, physical activity and parents' obesity on children's adiposity: a four-year longitudinal study. International Journal of Obesity 22, 758-764.

Malina RM (1995) Physical activity and fitness of children and youth: questions and implications. Medicine, Exercise, Nutrition and Health 4, 123-135.

Malina RM (1996) Tracking of physical activity and physical fitness across the lifespan. Research Quarterly for Exercise and Sport 67, Suppl. 3, S48-S57.

Marti B \& Vartiainen E (1989) Relation between leisure time exercise and cardiovascular risk factors among 15-year-olds in eastern Finland. Journal of Epidemiology and Community Health 43, 228-233.

Martínez ME, Giovannucci E, Spiegelman D, Hunter DJ, Willett WC \& Colditz GA (1997) Leisure-time physical activity, body size, and colon cancer in women: Nurses' Health Study
Research Group. Journal of the National Cancer Institute 89 948-955.

Martínez-González MA, Martínez JA, Hu FB, Gibney MJ \& Kearney J (1999) Physical inactivity, sedentary lifestyle and obesity in the European Union. International Journal of Obesity 23, 1192-1201.

Melanson EL \& Freedson PS (1996) Physical activity assessment: a review of methods. Critical Reviews in Food Science and Nutrition 36, 385-396.

Mensink GB, Deketh M, Mul MD, Schuit AJ \& Hoffmeister H (1996) Physical activity and its association with cardiovascular risk factors and mortality. Epidemiology 7, 391-397.

Montoye HJ, Kemper HCG, Saris WHM \& Washburn RA (1996) Measuring Physical Activity and Energy Expenditure. Champaign, IL: Human Kinetics.

Moore LL, Nguyen US, Rothman KJ, Cupples LA \& Ellison RC (1995) Preschool physical activity level and change in body fatness in young children. The Framingham Children's Study. American Journal of Epidemiology 142, 982-988.

Murgatroyd PR, Shetty PS \& Prentice AM (1993) Techniques for the measurement of human energy expenditure: a practical guide. International Journal of Obesity 17, 549-568.

Murphy MH \& Hardman AE (1998) Training effects of short and long bouts of brisk walking in sedentary women. Medicine and Science in Sports and Exercise 30, 152-157.

Must A, Jacques PF, Dallal GE, Bajema CJ \& Dietz WH (1992) Long-term morbidity and mortality of overweight adolescents. A follow-up of the Harvard Growth Study of 1992 to 1935 . New England Journal of Medicine 327, 1350-1355.

Must A \& Strauss RS (1999) Risks and consequences of childhood and adolescent obesity. International Journal of Obesity 23, Suppl. 2, S2-S11.

Nelson L, Jennings GL, Elser MD \& Kover PI (1986) Effects of changing levels of physical activity on blood pressure and haemodynamics in essential hypertension. Lancet i, 473-476.

Paeratakul S, Popkin BM, Keyou G, Adair LS \& Stevens J (1998) Changes in diet and physical activity affect the body mass index of Chinese adults. International Journal of Obesity 22, 424-431.

Paffenbarger RS, Hyde RT, Wing AL \& Hsieh CC (1986) Physical activity, all-cause mortality, and longevity of college alumni. New England Journal of Medicine 314, 605-613.

Paffenbarger RS, Wing AL, Hyde RT \& Jung D (1983) Chronic disease in former college students. XX. Physical activity and incidence of hypertension of college alumni. American Journal of Epidemiology 117, 245-257.

Pate RR (1993) Physical activity assessment in children and adolescents. Critical Reviews in Food Science and Nutrition 33, 321-326.

Pate RR, Baranowski T, Dowda M \& Trost SG (1996) Tracking of physical activity in young children. Medicine and Science in Sports and Exercise 28, 92-96.

Pate RR, Long BJ \& Heath G (1994) Descriptive epidemiology of physical activity in adolescents. Pediatric Exercise Science 6, 434-447.

Pate RR, Pratt M, Blair SN, Haskell WL, Macera CA, Bouchard C et al. (1995) Physical activity and public health: a recommendation from the Centers for Disease Control and Prevention and the American College of Sports Medicine. Journal of the American Medical Association 273, 402-407.

Pate RR \& Ross JG (1987) The national children and youth fitness study II: factors associated with health-related fitness Journal of Physical Education, Recreation and Dance 58, 93-95.

Philippaerts RM, Westerterp KR \& Lefevre J (1999) Doubly labelled water validation of three physical activity questionnaires. International Journal of Sports Medicine 20, 284-289. 
Powell KE, Thompson PD, Caspersen CJ \& Kendrick KS (1987) Physical activity and the incidence of coronary heart disease. Annual Review of Public Health 8, 253-287.

Prentice AM, Black AE, Coward WA, Davies HL, Goldberg GR, Murgatroyd PR, Ashford J, Sawyer M \& Whitehead RG (1986) High levels of energy expenditure in obese women. British Medical Journal 292, 983-987.

Prentice AM \& Jebb SA (1995) Obesity in Britain: gluttony or sloth? British Medical Journal 311, 437-439.

Racette SB, Schoeller DA \& Kushner RF (1995) Comparison of heart rate and physical activity recall with doubly labeled water in obese women. Medicine and Science in Sports and Exercise 27, 126-133.

Raitakari OT, Porkka KVK, Taimela S, Telema R, Räsänen L \& Viikari JSA (1994) Effects of persistent physical activity and inactivity on coronary risk factors in children and young adults. The Cardiovascular Risk in Young Finns Study. American Journal of Epidemiology 140, 195-205.

Reaven PD, Barrett-Conner E \& Edelstein S (1991) Relation between leisure-time physical activity and blood pressure in older women. Circulation 83, 559-565.

Remington PL, Smith MY, Williamson DF, Anda RF, Gentry EM \& Hogelin GC (1988) Design, characteristics, and usefulness of state-based behavioral risk factor surveillance: 1981-1987. Public Health Reports 103, 366-375.

Richardson MT, Leon AS, Jacobs DR, Ainsworth BE \& Serfass R (1994) Comprehensive evaluation of the Minnesota Leisure Time Physical Activity Questionnaire. Journal of Clinical Epidemiology 47, 271-281.

Riddoch CJ (1998) Relationships between physical activity and health in young people. In Young and Active, pp. 17-48 [SJH Biddle, JF Sallis and NC Cavill, editors]. London: Health Education Authority.

Riddoch CJ \& Boreham CAG (1995) The health-related physical activity of children. Sports Medicine 19, 86-102.

Riddoch CJ, Mahoney C, Murphy N, Boreham C \& Cran G (1991) The physical activity patterns of Northern Irish schoolchildren ages 11-16 years. Pediatric Exercise Science 3, 300-309.

Riddoch CJ, Murphy N, Nicholls A, van Wersche A \& Cran G (1990) The Northern Ireland Health and Fitness Survey. Belfast: The Queen's University of Belfast.

Rissanen AM, Heliövaara M, Knekt P, Reunanen A \& Aromaa A (1991) Determinants of weight gain and overweight in adult Finns. European Journal of Clinical Nutrition 45, 419-430.

Robinson TN, Hammer LD, Killen JD, Kraemer HC, Wilson DM, Hayward C \& Taylor CB (1993) Does television viewing increase obesity and decrease physical activity? Cross-sectional and longitudinal analyses among adolescent girls. Pediatrics 91, 273-280.

Robinson TN \& Killen JD (1995) Ethnic and gender differences in the relationships between television viewing and obesity, physical activity, and dietary fat intake. Journal of Health Education 26, Suppl., 91-98.

Ross JG \& Gilbert GG (1985) The National Children and Youth Fitness Study: a summary of findings. Journal of Physical Education, Recreation and Dance 56, 45-50.

Rowland TW (1996) Is there a scientific rationale supporting the value of exercise for the present and future cardiovascular health of children? The con argument. Pediatric Exercise Science 8, 303-309.

Sallis JF (1993) Epidemiology of physical activity and fitness in children and adolescents. Critical Reviews in Food Science and Nutrition 33, 403-408.

Sallis JF (2000) Age-related decline in physical activity: a synthesis of human and animal studies. Medicine and Science in Sports and Exercise 32, 1598-1600.
Sallis JF, Condon SA, Goggin KJ, Roby JJ, Kolody B \& Alcarez JE (1993) The development of self-administered physical activity surveys for 4th grade students. Research Quarterly for Sport and Exercise 64, 25-31.

Sallis JF, Haskell WL, Wood PD, Fortmann SP, Rogers T, Blair SN \& Paffenbarger RS (1985) Physical activity assessment methodology in the Five-City Project. American Journal of Epidemiology 121, 91-106

Sallis JF \& Hovell MF (1990) Determinants of exercise behaviour. Exercise and Sports Science Reviews 18, 307-330.

Sallis JF, Hovell MF, Hofstetter CR, Faucher P, Elder JP, Blanchard J, Caspersen CJ, Powell KE \& Christensen GM (1989) A multivariate study of determinants of vigorous exercise in a community sample. Preventive Medicine 18, 20-34.

Sallis JF \& Owen N (1999) Physical Activity and Behavioral Medicine. Thousand Oaks, CA: Sage.

Sallis JF \& Patrick K (1994) Physical activity guidelines for adolescents: consensus statement. Pediatric Exercise Science $\mathbf{6}$, 302-314.

Saris WHM (1985) The assessment and evaluation of daily physical activity in children: a review. Acta Paediatrica Scandinavica 318, 37-48.

Saris WHM (1986) Habitual physical activity in children: methodology and findings in health and disease. Medicine and Science in Sports and Exercise 18, 253-263.

Schoeller DA \& Racette SB (1990) A review of field techniques for the assessment of energy expenditure. Journal of Nutrition $\mathbf{1 2 0}$, 1492-1495.

Schonfeld-Warden N \& Warden CH (1997) Pediatric obesity: an overview of etiology and treatment. Pediatric Clinics of North America 44, 339-361.

Serdula MK, Ivery D, Coates RJ, Freedman DS, Williamson DF \& Byers T (1993) Do obese children become obese adults? A review of the literature. Preventive Medicine 22, 167-177.

Shah M \& Jeffery RW (1991) Is obesity due to overeating and inactivity, or to a defective metabolic rate? A review. Annals of Behavioral Medicine 13, 73-81.

Shannon B, Peacock J \& Brown MJ (1995) Body fatness, television viewing and caloric-intake of a sample of Pennsylvania Sixth Grade Children. Journal of Nutrition Education 23, 262-268.

Shephard RJ (1986) Fitness of a nation: lessons from the Canada Fitness Survey. Medicine and Sports Science 22, 116-131.

Shields DLL \& Bredemeier BJL (1994) Character Development and Physical Activity. Champaign, IL: Human Kinetics.

Simoes EJ, Byers T, Coates RJ, Serdula M, Mokdad AH \& Heath GW (1995) The association between leisure-time physical activity and dietary fat in American adults. American Journal of Public Health 85, 240-244.

Simons-Morton B, O'Hara N, Simons-Morton D \& Parcel G (1987) Children and fitness: A public health perspective. Research Quarterly for Exercise and Sport 58, 295-302.

Slattery ML, McDonald A, Bild DE, Caan BJ, Hilner JE, Jacobs DR \& Liu K (1992) Associations of body fat and its distribution with dietary intake, physical activity, alcohol, and smoking in blacks and whites. American Journal of Clinical Nutrition 55, 943-949.

Sleap M \& Tolfrey K (2001) Do 9- to 12 yr-old children meet existing physical activity recommendations for health? Medicine and Science in Sports and Exercise 33, 591-596.

Sport England (2000) Young People and Sport in England 1999. London: Sport England.

Stager JM, Lindeman A \& Edwards J (1995) The use of doubly labelled water in quantifying energy expenditure during prolonged activity. Sports Medicine 19, 166-172.

Stephens T (1988) Physical activity and mental health in the United States and Canada: evidence from four population surveys. Preventive Medicine 17, 35-47. 
Stephens T \& Caspersen CJ (1994) The demography of physical activity. In Physical Activity, Fitness and Health, pp. 204-213 [C Bouchard, RJ Shephard and T Stephens, editors]. Champaign, IL: Human Kinetics.

Steptoe A \& Butler N (1996) Sports participation and emotional well being in adolescents. Lancet 347, 1789-1792.

Sunnegardh J, Bratteby L-E, Hagman U, Samuelson G \& Sjolin S (1986) Physical activity in relation to energy intake and body fat in 8- and 13-year old children in Sweden. Acta Paediatrica Scandinavica 75, 955-963.

Taylor CB, Sallis JF \& Needle R (1985) The relationship of physical activity and exercise to mental health. Public Health Reports 100, 195-201.

Taylor WC, Blair SN, Cummings SS, Wun CC \& Malina RM (1999) Childhood and adolescent physical activity patterns and adult physical activity. Medicine and Science in Sports and Exercise 31, 118-123.

Telema R \& Yang X (2000) Decline of physical activity from youth to young adulthood in Finland. Medicine and Science in Sports and Exercise 32, 1617-1622.

Tell GS \& Vellar OD (1988) Physical fitness, physical activity and cardiovascular disease risk factors in adolescents: the Oslo Youth Study. Preventive Medicine 17, 12-24.

Torun B, Davies PSW, Livingstone MBE, Paolisso M, Sackett R \& Spurr GB (1996) Energy requirements and dietary energy recommendations for children and adolescents 1 to 18 years old. European Journal of Clinical Nutrition 50, Suppl. 1, S37-S81.

Treuth MS, Adolph AL \& Butte NF (1998) Energy expenditure in children predicted from heart rate and activity calibrated against respiration calorimetry. American Journal of Physiology 275, E12-E18.

Troiano RP, Flegal KM, Kuczmarski RJ, Campbell SM \& Johnson CL (1995) Overweight prevalence and trends for children and adolescents: The National Health and Nutrition Examination Surveys, 1963 to 1991. Archives of Pediatrics and Adolescent Medicine 149, 1085-1091.

Troiano RP, Macera CA \& Ballard-Barbash R (2001) Be physically active each day. How can we know? Journal of Nutrition 131, 451S-460S.

Troisi RJ, Heinold JW, Vokonos PS \& Weiss ST (1991) Cigarette smoking, dietary intake, and physical activity: effects on body fat distribution - the Normative Aging Study. American Journal of Clinical Nutrition 53, 1104-1111.

Trost SG (2001) Objective measurement of physical activity in youth: current issues, future directions. Exercise and Sport Sciences Reviews 29, 32-36.

Tucker LA (1986) The relationship of television viewing to physical fitness and obesity. Adolescence 21, 797-806.

Twisk JWR, Kemper HCG, van Mechelen W, Post GB \& van Lenthe FJ (1998) Body fatness: longitudinal relationship of body mass index and the sum of skinfolds with other risk factors for coronary heart disease. International Journal of Obesity 22, 915-922.

Twisk JWR, van Mechelen W, Kemper HCG \& Post GB (1997) The relation between 'long-term exposure' to lifestyle during youth and young adulthood and risk factors for cardiovascular disease at adult age. Journal of Adolescent Health 20, 309-319.

US Department of Agriculture, Agricultural Research Service, Dietary Guidelines Advisory Committee (2000) Report of the Dietary Guidelines Advisory Committee on the Dietary Guidelines for Americans, 2000. http://www.health.gov/ dietaryguidelines/dgac/

US Department of Health and Human Services (1996) Physical Activity and Health: A Report of the Surgeon General, US Department of Health and Human Services, Centers for Disease Control and Prevention. Atlanta, GA: National Center for Chronic Disease Prevention and Health Promotion.
Vaccaro P \& Mahon AD (1989) The effects of exercise on coronary heart disease risk factors in children. Sports Medicine 8, 139-153.

Vanhala M, Vanhala P, Kumpusalo E, Halonen P \& Takala J (1998) Relation between obesity from childhood to adulthood and the metabolic syndrome: population based study. British Medical Journal 317, 319.

van Mechelen W, Twisk JWR, Post GB, Snel J \& Kemper HCG (2000) Physical activity of young people; the Amsterdam Longitudinal Growth and Health Study. Medicine and Science in Sports and Exercise 32, 1610-1616.

Voorrips LE, Meijers JHH, Sol P, Seidell JC \& van Staveren WA (1991) History of body weight and physical activity of elderly women differing in current physical activity. International Journal of Obesity 16, 199-205.

Wannamethee G \& Shaper AG (1992) Physical activity and stroke in British middle-aged men. British Medical Journal 304, 597-601.

Wareham NJ, Hennings SJ, Prentice AM \& Day NE (1997) Feasibility of heart-rate monitoring to estimate total level and pattern of energy expenditure in a population-based epidemiological study: the Ely young cohort feasibility study 1994-1995. British Journal of Nutrition 78, 889-900.

Wareham NJ \& Rennie KL (1998) The assessment of physical activity in individuals and populations: Why try to be more precise about how physical activity is assessed? International Journal of Obesity 22, Suppl. 2, S30-S38.

Webber LS, Osganian SK, Feldman HA, Wu M, McKenzie TL, Nichaman M, Lytle LA, Edmundson E, Cutler J, Nader PR \& Luepker RV (1996) Cardiovascular risk factors among children after a two and a half year intervention - The CATCH Study. Preventive Medicine 25, 432-441.

Welk GJ \& Corbin CB (1995) The validity of the Tritrac - R3D Activity Monitor for the assessment of physical activity in children. Research Quarterly for Exercise and Sport 66, 202-209.

Welk GJ, Corbin CB \& Dale D (2000) Measurement issues in the assessment of physical activity in children. Research Quarterly for Exercise and Sport 71, Suppl., 59-73.

Welk GJ, Corbin CB \& Kampert JB (1998) The validity of the Tritrac-R3D activity monitor for the assessment of physical activity: II. Temporal relationships among objective assessments. Research Quarterly for Exercise and Sport 69, 395-399.

Weller I \& Corey P (1998) The impact of excluding non-leisure energy expenditure on the relation between physical activity and mortality in women. Epidemiology 9, 632-635.

Westerterp KR (1999a) Assessment of physical activity level in relation to obesity: current evidence and research issues. Medicine and Science in Sports and Exercise 31, Suppl., S522-S525.

Westerterp KR (1999b) Physical activity assessment with accelerometers. International Journal of Obesity 23, Suppl. 3, 45-49.

Westerterp KR \& Bouten CVC (1997) Physical activity assessment: comparison between movement registration and doubly labeled water method. Zeitschrift für Ernährungswissenschaft 36, 263-267.

Whitaker RC, Wright JA, Pepe MS, Seidel KD \& Dietz WH (1997) Predicting obesity in young adulthood from childhood and parental obesity. New England Journal of Medicine 337, 869-873.

Wickham CAC, Walsh K, Cooper C, Barker DJP, Margetts BM, Morris J \& Bruce SA (1989) Dietary calcium, physical activity, and risk of hip fracture: a prospective study. British Medical Journal 299, 889-892.

Williams PT (1997) Evidence for the incompatibility of age-neutral overweight and age-neutral physical activity standards for runners. American Journal of Clinical Nutrition 65, 1391-1396.

Williamson DF, Madans J, Anda RF, Kleinman JC, Kahn HS \& Byers T (1993) Recreational physical activity and ten-year 
weight change in a US national cohort. International Journal of Obesity 17, 279-286.

Wing RR (1999) Physical activity in the treatment of adult overweight and obesity: current evidence and research issues. Medicine and Science in Sports and Exercise 31, Suppl., S547-S552.

Wolf AM, Gortmaker SL, Cheung L, Gray HM, Herzog DB \& Colditz GA (1993) Activity, inactivity, and obesity: racial, ethnic, and age differences among schoolgirls. American Journal of Public Health 83, 1625-1627.

Wong MY, Day NE \& Wareham NJ (1999) Measurement error in epidemiology: the design of validation studies II: the multivariate situation Statistics in Medicine 18, 2831-2845.

Wong ND, Hei TK, Qaqundah PY, Davidson DM, Bassin SL \& Gold KV (1992) Television viewing and pediatric hypercholesterolemia. Pediatrics 90, 75-79. 